\title{
INTRODUCTION TO A CORPUS OF MIDDLE ENGLISH ALCHEMICAL POETRY
}

\section{Alchemical Poetry in Late Medieval England}

In the fifteenth century, on the threshold of the early modern period, England witnessed tremendous political, social and cultural change. The universities of Oxford and Cambridge operated amidst a growing number of academic institutions in the British Isles and in continental Europe-the Scottish universities of St. Andrews (1411) and Glasgow (1451) were part of a surge of new academic foundations - and headed the vibrant international scholarly exchange characteristic of the pre-Reformation period. The scholarly study of natural philosophy thrived alongside medical doctors' attempts to contain epidemics, a general enthusiasm for astrological intelligence and its applications, and an increasingly vigorous flow of scientific information to a wider range of audiences. Scientific communication evolved amidst the contemporary cultivation of poetry that inspired Chaucer's successors, John Lydgate and Thomas Hoccleve, as well as James I of Scotland. ${ }^{1}$ Meanwhile, craftsmen continued to work under the guardianship of the guilds while adding literacy to their set of professional skills.

Alchemy, a craft based on an intricate theoretical system, intersected naturally with university disciplines concerned with natural philosophy on a theoretical level, and with some crafts on a practical level. Not organised in a guild, it was commonly practised both by those who came into contact with alchemical lore in bibliophilic environments (scholars, clerics, medical doctors, etc.) and by craftsmen engaged with metals, furnaces and the modification of substances (smelters, smiths and workers in the mining industry). Sophistication of practice and individual emphasis on theory or practice necessarily varied between these groups as well as from one individual to another. But in the fifteenth century in particular craftsmen with alchemical leanings refined their knowledge in a newly revived combination of word and deed, in the workshop and on paper. It was in this environment, and

\footnotetext{
${ }^{1}$ For a wider perspective on poetry in the English Renaissance see Marotti, Manuscript.
} 
in the course of just a few decades, that Middle English alchemical poetry became the most emblematic, successful and current expression of the craft and its teachings. ${ }^{2}$

The written world of alchemy into which alchemical poetry was introduced looked back upon a relatively homogeneous tradition. Although medieval manuscripts may be quite diverse in content and written expression, it is possible to discern two main types of medieval alchemical literature: firstly, ancient, traditional, Arabic or Greek texts, often theoretical in nature. These ancient texts had passed easily into the Latin tradition of the Middle Ages, which added large corpora of pseudonymous alchemica, populated under the names of ancient authorities, to the body of literature. ${ }^{3}$ They continued to be circulated, adapted and applied in the fifteenth century. This part of alchemical literature (both ancient and imitated) was associated closely with the high culture of writing, monasteries and, in the later Middle Ages, academic contexts. Secondly, medieval alchemical literature included texts written in, and for, the workshop. This pragmatic, applied body of texts consists of recipes and working notes, often of more imminent and recent origin than the traditional texts mentioned before. They were frequently noted down either in blank spaces of theoretical manuscripts or, as time passed, in dedicated volumes and craft recipe collections, so-called books of secrets, many of which are lost to the historical record. ${ }^{4}$ It was particularly this latter branch of alchemical writing that produced Middle English alchemical verse.

If a novelty in alchemical writing in the fifteenth century, Middle English alchemical poetry was nevertheless based on an ancient tradition, one that defined its genre and medium: like all medieval scientific poetry alchemical verse evolved as an adaptation, imitation, translation and continuation of classical didactic poetry. ${ }^{5}$ Poetry had been the preferred educational medium of classical Rome and was reintroduced to the canon of elevating and instructive writings in the course of the humanist revival of late

2 Pioneering research on alchemical verse includes Schuler, English Magical; and Schuler, Alchemical Poetry. The most comprehensive and recent survey of alchemical verse is Kahn, "Alchemical Poetry" (Parts I and II).

${ }^{3}$ See the Introduction and Chapter 3 for details.

${ }^{4}$ A prominent book of secrets and the historian's task of discovering the practice behind the texts forms are discussed in Smith and Beentjes, "Nature and Art". On books of secrets see Eamon, Science; and the individual contributions in Leong and Rankin, Secrets, esp. Smith, "What is a Secret?".

5 Timmermann, "Scientific and Encyclopaedic Verse". Early Byzantine and Arabic alchemical poetry is discussed in Schuler, Alchemical Poetry, xxvi-xxvii. 
medieval Europe. Didactic poems by Lucretius and Pliny, Manilius and pseudo-Aristotle enjoyed a particularly enthusiastic reception. ${ }^{6}$ The world of knowledge preserved in the extensive body of medieval scientific poetry developed to be rather more inclusive than either an ancient or a modern concept of science and its objects would imply. Poetic works relating to medicine and botany, to astronomy, astrology and cosmology, were joined by technical poetry, e.g. on masonry, by rhymed culinary recipes and household books, by grammatical rules and other items related to academic education and the artes proper, as well as encyclopaedic poetry, an extensive digest of various branches of scientific knowledge. ${ }^{7}$ Writers of the late medieval and early modern periods also accepted alchemical recipes among the subjects worthy of versification, both enthusiastically and for the last time in history.

A vernacular tradition of scientific poetry emerged from the fourteenth century onwards. In England in particular this proved to be a successful format for the preservation of alchemical lore. Vernacular alchemical poetry throughout continental Europe pales before the sheer volume, variety and consistency of Middle English alchemica. German alchemical verse, for instance, favoured not practical recipes or extensive explanations but mostly comprised received knowledge about alchemy in useful phrases and pithy maxims, so-called gnomic texts. ${ }^{8}$ The more wordy, Italian form of alchemical poetry flourished in the Renaissance in imitation of Latin didactic poetry. In France the Roman de la Rose determined the style and reception of alchemy in verse to a significant extent. But across the continent alchemical verse would never quite achieve the ubiquity enjoyed by its English equivalents. ${ }^{9}$

Notably, the range of subjects covered in Middle English scientific poetry is not identical to that of scientific prose. Poetry and prose were considered complementary and not necessarily interchangeable by both writers and readers. Also, different disciplines employed verse to a different degree. Although medicine was by far the most popular topic for scientific texts in fifteenth-century England, and indeed throughout Europe, medical

\footnotetext{
${ }^{6}$ For a comprehensive history of didactic poetry see Schuler and Fitch, "Theory and Context".

${ }^{7}$ Scientific manuscripts including such items in the fifteenth century are described, e.g., in Voigts, "Scientific" and Keiser, Works of Science.

8 Telle, Sol und Luna.

${ }^{9}$ Kahn, "Alchemical Poetry" II, 254f. and $264 \mathrm{ff}$. The heterogeneous development of alchemical verse in Europe and its conditions are yet to be investigated in scholarship.
} 
theoretical texts only occasionally took verse form. ${ }^{10}$ Yet generally the sudden thirst for scientific information in Middle English, particularly in verse, by a growing audience (now including a newly literate public, university scholars, noblemen and craftsmen) fuelled the production of scientific writing further. ${ }^{11}$ The fifteenth century produced roughly six times more texts (prose and verse) than the fourteenth century, a body of writing which included a much higher proportion of vernacular texts and an unanticipated number of scientific poems. ${ }^{12}$

Recipe texts were particularly prone to the textual transformations typical of the fifteenth century: versification and vernacularisation. Like the majority of medieval alchemical poetry, the corpus of poems at the centre of this book comprises recipes for the philosophers' stone, ${ }^{13}$ the ultimate product of alchemy that was believed to remove all imperfection from substances as well as the human body. However, the general late medieval penchant for rhymed recipes applied to all branches of scientific learning. Hundreds of Middle English pragmatic alchemical, medical and culinary recipes survive, as well as secreta and instructions for mixing inks or making vessels. ${ }^{14}$ These last, in turn, have material points of contact with alchemical recipe literature: they describe methods for producing equipment necessary for the practice and writing of alchemy.

This enthusiasm for verse recipes may, in part, have been motivated by practical considerations. Practising alchemists in particular, among them a large group of craftsmen not fluent in Latin, may have found using a recipe from memory easier when ingredients and methods could be recalled in pairs of rhymes. ${ }^{15}$ The poetic form lent itself to carrying information from

\footnotetext{
${ }^{10}$ Jones, "Information and Science," 101; Keiser, Works of Science, 301; see also Robbins, "Medical Manuscripts".

${ }^{11}$ On literacy see e.g. Parkes, "Literacy" and Jones, Vernacular.

12 Jones, "Information and Science," 100-101. Also Taavitsainen and Pahta, "Vernacularisation" and Voigts, "Multitudes".

13 The position of the apostrophe in the term 'philosophers' stone' (stone of the [natural] philosophers) should be noted. The term's origin is unclear, as explained in the $O E D$, s.v. 'philosopher's stone' (10/2010): it is referred to simply as (noster) lapis, '(our) stone', in medieval Geberian writings. Albertus Magnus called it lapis quem philosophi laudant ubique, "the stone which the philosophers everywhere laud", thus possibly originating the term lapis philosophorum.

14 Recipes and their genre are analysed in Carroll, "Middle English Recipe," which includes a comprehensive bibliography for culinary, medical and alchemical recipes on pp. 41-42; Grund, "Golden Formulas," Stannard, "Rezeptliteratur" and Telle, "Rezept".

${ }^{15}$ On the mnemonic functions of (didactic) verse from the fifteenth century onwards see Voigts and McVaugh, Latin Technical Phlebotomy, 19; Schuler and Fitch, "Theory and Context,"
} 
page to furnace. For copyists of alchemica the medium of verse held similar merits. Rhythm and rhyme as mnemonic aids allowed the transmission of text from one manuscript to another without the danger of skipping a line or phrase by accident. ${ }^{16}$ Other merits of employing the poetic medium include its potential in attracting patrons for the alchemical work. This function developed more fully in the sixteenth and seventeenth centuries in the form of dedicatory poems prefacing alchemical prose, or the production of presentation copy manuscripts containing alchemical poetry. ${ }^{17}$ It does not, however, apply to the core corpus of texts discussed in the remainder of this book. Overall, as the most popular branch of scientific poetry in fifteenth-century England, alchemical poetry is more emblematic of the period than scholarly prose texts or other scientific or non-scientific verse in many respects. Alchemy now spoke not just the language of the man outside the university, but also in a rhythmic, melodious voice.

A consideration of the material manifestation of alchemical verse in pragmatic, notebook-like manuscripts enlightens our understanding of its uses, dissemination, and indeed its authors' envisaged audiences further. It is worth noting here that alchemical manuscripts, including those containing alchemical poems, are in some respects different from their other scientific counterparts. Alchemical readers and writers used a fairly specific form of terminology and expression to navigate a growing body of alchemica, one that might have restricted the nature of volumes in which alchemical verse might be recorded. But since alchemical poetry in particular provided an ideal template for the ordering of thoughts and experiments from the fifteenth century onwards, with time, it entered a wide variety of manuscripts. Alchemical verse could be found on scholars' bookshelves and in artisans' and practising alchemists' workshops. It was read by physicians as well as miners and goldsmiths, and altered, wittingly or unwittingly, in spelling, wording or even structurally, by all audiences. The body of alchemical poetry thus reflects the contexts of its production and reception. Each copy was a unique product, a mixture of an exemplar's model and a copyist's reading of the same, of theoretical beliefs and practical considerations..$^{18}$ Therefore,

25; Taavitsainen, "Transferring," $38-39$, who also refers to a study on the different audiences for prose (learned) and verse (broader): Blake, Form of Living.

16 Schuler, Alchemical Poetry, xxxiv-xxxv.

17 Schuler, Alchemical Poetry, xxxiv-xlii, esp. xxxvi-xxxviii, and Kahn, "Alchemical Poetry" II, 63-64, the latter a distillation of existing theories on functions of alchemical poetry.

18 On medieval scribal processes see Parkes, Scribes; repercussions of scribal unfamiliarity with alchemy are mentioned in Principe, Secrets, 53; the traits of more expert copyists with 
perhaps more than the academic art of medicine and other scholarly disciplines, the written heritage of alchemy constitutes evidence of the interactions between theory, practice and texts. ${ }^{19}$

In linguistic terms, alchemical poets used characteristic styles, motifs, verse-forms and structural elements. Some of these naturally intersected with the expression of alchemical prose. It had long been believed that only a worthy alchemist would be able to understand a recipe and discover the secrets of nature behind alchemy's obscure, metaphorical terminology and expression. In the fifteenth century copyists and readers of vernacular alchemica and the growing body of alchemical verse found themselves forced to interpret alchemical terminology derived from the Arabic, Greek and Latin in Middle English terms. ${ }^{20}$ Here alchemical poetry became instrumental in the refinement of a scientific terminology in Middle English. Rhyme words provided unfamiliar terms with a phonetic point of reference. They also drew the copyist's attention to important information, which was often placed towards the end of lines. The transition of alchemical terms into Middle English, and thus of alchemical concepts and thought into a living language's referencing system, thus occurred successfully, consistently and memorably in verse.$^{21}$ For the remainder of the active period of circulation for alchemical literature, which lasted well into the seventeenth century and beyond, the detectable alchemical poetic idiom remained remarkably stable. ${ }^{22}$ Only the appearance and increasing dominance of chemistry among the sciences, now striving to be modern in approach and symbolic formulae, banished poetry from the study of nature and separated literature from science.

In terms of famous authors, fifteenth-century England brought forth two alchemist poets whose names and works have dominated the historical impression of their period: Thomas Norton and George Ripley. Norton

a vested interest in alchemy, such as those described here, will emerge in the case studies especially of Chapters 5 and 6 below.

19 This also emerges variously in studies of alchemical manuscripts across Europe (see e.g. Kassell, Medicine and Magic, Láng, Unlocked Books, or Patai, Jewish Alchemists) and in manuscripts like those containing texts from the corpus of poems discussed in this book (especially their annotations). See particularly Chapters 5 and 6 below.

${ }^{20}$ Pereira, "Alchemy".

${ }^{21}$ On the development of Middle English technical languages for scientific texts see also Schleissner, Manuscript Sources, esp. Voigts, "Multitudes". The case of alchemy and its terminology is yet to be studied exhaustively.

22 This may be observed in the development of the texts edited in the Appendix below. See also Chapter 2, especially the section entitled "Textual variation and corpus connections". 
(ca. 1433-1513/14), Bristolian municipal officer and courtier (and at one point adviser to Edward IV), wrote the "Ordinal of Alchemy", the only text attributed to him, in the final quarter of the fifteenth century. A single substantial poem of 3,102 lines plus preface, the "Ordinal" ensured Thomas Norton's role as a figurehead for English alchemy in the fifteenth century from its early reception onwards. ${ }^{23}$ Like Norton, George Ripley (d. ca. 1490) is a historical alchemical author whose poetic oeuvre eventually superseded his persona. Ripley was canon regular of Bridlington priory in Yorkshire and is said to have travelled to Louvain (Flanders) and Italy to study with masters of the arts and alchemy. ${ }^{24}$ But his sizeable body of alchemical poetry, and his later pseudonymous oeuvre, have preserved his name in history much more forcefully. Ripleian works present mostly an adaptation of Latin sources using alchemical principles commonly attributed to thirteenthcentury philosopher and doctor Raymond Lull (whose name, attached to a greatly successful pseudonymous textual tradition, defined alchemical literature in the fourteenth and fifteenth centuries). ${ }^{25}$ They also purport to preserve Ripley's own laboratory experiences. Among Ripley's best known works are the "Compound of Alchemy" (also known as "The Twelve Gates") ${ }^{26}$ the "Mystery of Alchemists", ${ }^{27}$ and a number of other alchemical poems. These, the vast, extended pseudo-Ripleian corpus dating from the late fifteenth and sixteenth centuries onwards, and the illuminated scrolls bearing alchemical poems now known as 'Ripley Scrolls', will become relevant for the history of the corpus of poems discussed in this book. By the early modern period the iconic Middle English alchemical poet George Ripley had thus joined the ranks of the very authorities he emulated.

Beyond and including Thomas Norton and George Ripley the tradition of vernacular alchemical poetry was defined by spurious or changing attributions to both ancient and contemporary authorities. More often than not poems were circulated without the name of an author attached. The reasons

23 Not much is known about Thomas Norton's life, and his biography has been rewritten and refuted several times; see Reidy, Thomas Norton's Ordinal. The "Ordinal of Alchemy" is NIMEV 3772; editions are reproduced in Reidy and in $T C B, 1-106$. An early modern German verse translation is the anonymous Chymischer Tractat Thomas Nortoni (1625).

24 On Ripley see Principe, "Ripley, George," and Rampling, esp. “Catalogue," 126, fn. 2, which details the history of Ripley biographies. These are more useful than information given in the only modern edition of Ripley's work to date (apart from Taylor, “George Ripley's Song"): Ripley, Compound (ed. Linden).

25 On the pseudo-Lullian corpus of works see Pereira, Alchemical Corpus.

26 NIMEV 595; TCB, 107-193.

27 This is part of the corpus around the "Verses upon the Elixir"; see below. 
for this strong tendency towards anonymity are relatively straightforward: as Gebrauchstexte proper (practical instructions without literary pretensions) most alchemical poems did not require a fixed named author to lend authority to their contents. Readers and copyists selected useful contemporary recipes and theoretical texts by different criteria, like genre and language. ${ }^{28}$ The circulation of alchemical knowledge and the reception of texts differed in contemporary and canonical alchemical literature. As such, Middle English alchemical poetry in particular constitutes an immediate witness of the contemporary understanding of alchemical substances, methods and theory on one hand, and their translation into writing, and practice, on the other. Anonymous alchemical verse provides a direct glimpse into the production, communication and circulation of both theoretical and practical knowledge. ${ }^{29}$

It is not only because of the traditional historiographical focus on famous authors, alchemists and works, but perhaps also due to the modern separation of poetry, alchemy and science that scholarship has neglected-and, at times, even scorned-alchemical poetry. To the modern eye its literary merits pale before the poems of Chaucer, Gower and their fifteenth-century peers. In his monumental History of Magic and Experimental Science, Lynn Thorndike famously dismissed the work of George Ripley as "very stupid and tiresome reading". ${ }^{30}$ In the fifteenth century, however, scientific and other poetry was much more integrated and formed different parts of the same body of Middle English writing. At times they even intersected: Chaucer's oeuvre, the Romaunt de la Rose and Lydgate's verse regimen entitled Dietary (which, incidentally, turned out to be Lydgate's most popular work during and immediately following his lifetime) are prime examples of medical themes in literary verse written by poets without a professional interest in natural philosophy. ${ }^{31}$ Conversely the style and language of alchemical poems written by alchemical practitioners without any literary ambitions resemble those of the Middle English poetic oeuvre to a remarkable extent. Scientific, alchemical and literary poems all participated in the development of the Middle English language and expression. They also often shared space in contemporary manuscripts. Finally, the scientific reception of specific passages in otherwise literary works and the artistic appreciation of scien-

28 These issues will be explored in detail in later parts of this book.

29 See also Kahn, "Alchemical Poetry" II, 63-64.

30 Thorndike, History of Magic, IV, 352.

31 The role of Chaucer on late medieval/early modern perceptions of science, poetry and authors is discussed in Chapter 3 below. 
tific poetry also testify to the original interactions between the disciplines. ${ }^{32}$ Scientific, and thus alchemical, poetry was an integral part of the written culture of fifteenth-century England.

The afterlives of Middle English alchemical poems are distinctive, even if they pale before the thriving late medieval and early modern manuscript tradition of poetry. ${ }^{33}$ While manuscript production and reception continued well into the seventeenth century, alchemical verse did not enjoy an early representation in print, the medium whose invention left a most distinguishing mark on the latter part of the fifteenth century. Much of the Middle English alchemical poetic oeuvre, such as pragmatic recipes and mnemonic rhymes, was probably considered too practical, ordinary or ephemeral to be printed together with a carefully selected body of works intended to preserve a legacy of human knowledge. ${ }^{34}$ By the time some alchemical poems materialised in printed volumes, particularly in English, the genre itself had almost turned into history. ${ }^{35}$ Elias Ashmole's Theatrum Chemicum Britannicum (TCB), a compendium of alchemical verse published in $165^{2}$ as an homage to the English language, marks the beginning proper of the published body of alchemical poetry as well as its epitome. ${ }^{36}$ Thanks to Ashmole's bibliophilic (rather than purely linguistic), historically sensitive interest in alchemy and poetry, his compendium includes works by Thomas Norton and George Ripley as well as Chaucer's "Canon's Yeoman's Tale" and many of the poems which form the focus of this book. As such, Ashmole's collection, both the printed book and the underlying manuscript collection, may be considered the final resting place of the body of alchemical poetry of medieval England. ${ }^{37}$

\section{The Corpus Around the "Verses UPON THE EliXIR"}

The late medieval alchemical poem "Verses upon the Elixir" (henceforth also "Verses") played a vital part in the communication of alchemical knowledge

\footnotetext{
${ }^{32}$ See, for example, BL MS Sloane 320 (s. $\mathrm{xvi}^{\mathrm{ex}}$ ), which contains the conclusion of Chaucer's "Canon's Yeoman's Tale" (f. $34^{v}$ ) together with alchemica by George Ripley.

${ }^{33}$ The term 'afterlives' is adapted here loosely from the term relating to the late preservation and reception of historical letters; see e.g. Daybell, Material Letter, chapter 8.

${ }^{34}$ See also Timmermann, "Introduction".

35 The first Latin collection of alchemica is Zetzner, Theatrum Chemicum (1602-1661).

${ }^{36} \mathrm{Kahn}$, "Alchemical Poetry" I, 255-256; TCB.

37 Ashmole's preparatory manuscripts now form a substantial part of the Ashmolean Library's collections at Oxford (Bod MSS Ashmole 971 and 972).
} 
in the fifteenth through seventeenth centuries. It was written, copied, read, annotated, interpreted, tried and tested, dismissed or accepted, and certainly constantly discussed by readers and writers with alchemical interests. Within contemporary networks of written knowledge, the poem "Verses upon the Elixir" not only represents a prime example of its genre, but, as will become clear throughout this book, a central work utilised by early modern scribes and readers to discover the correct procedure for making the philosophers' stone. Moreover, its users considered the "Verses upon the Elixir" not a stand-alone text, but a poem to be consulted, altered and digested in comparison with other alchemica. These associated texts form a corpus around the "Verses upon the Elixir", a microcosm of written alchemical thought containing clues about how their users thought, wrote and practised alchemy. It is this corpus that is at the heart of this book. The reconstruction of its texts' (and thus their writers') interactions presented in this chapter will both aid the development of case studies in later chapters of this book and, generally, prove useful for an understanding of how alchemical ideas were circulated and received in late medieval and early modern England.

A Middle English rhymed recipe of up to 194 lines, the poem "Verses upon the Elixir" formed connections with a large number of contemporary and ancient alchemica through proximity in manuscripts, in language or content, and in the contemporary perception of the body of alchemical literature. At least fifteen texts and their variants are related to the "Verses upon the Elixir" (NIMEV 3249). The nature of their connections with the "Verses" divides them into several groups: "Boast of Mercury", "Mystery of Alchemists" and "Liber Patris Sapientiae" (NIMEV 1276, 4017, 1150.3) are poems whose text coincides with parts of the "Verses". The poems "Exposition" and "Wind and Water" (NIMEV 2666 and 3257) form bonds with the "Verses" by virtue of being appended to the poem in manuscripts. The set of poems now gathered under the title of "Richard Carpenter's Work" (NIMEV $2656 ; 3255.7 ; 1558)$ is connected with the "Verses upon the Elixir" through intertextuality; those appearing together with "Richard Carpenter's Work" on the "Ripley Scrolls' (NIMEV 2688.7 ("On the ground"); 1561.7 ("In the sea"); 1364.5 ("I shall you tell")) form an extension of this group. Peripheral additions to the corpus are poems resembling the "Verses upon the Elixir" on a poetic, linguistic level: "Short Work" (NIMEV 3721) and "Trinity" (NIMEV 1558.5). It should be noted that all texts mentioned appear overwhelmingly in manuscripts together with other corpus texts: their affiliation with the corpus identified here is both material and linguistic in nature. Three sixteenth-century prose texts, a translation of the "Verses upon the 
Elixir" ("Terra Terrae Philosophicae") and two commentaries on the poem ("Lead" and "Thomas Hend"), provide the final links in the chain. ${ }^{38}$

As products of a textual evolutionary process over the course of two centuries, the corpus and its cross-connections are fairly complex. Naturally the origins and interactions of these texts could not be fully explained in terms of causality, origin and succession. However, for the present purpose of introducing the corpus and its individual texts as objects of historical investigation, the clustering of poems according to their manner of association with the "Verses" (as suggested above) will provide a practical way of managing information about the corpus.

Texts belonging to the corpus around the "Verses upon the Elixir" survive in more than one hundred manuscripts dating from the mid-fifteenth to the later seventeenth century, numbering more than 400 copies of these texts in total. An ever-changing, written and thus documented reception accompanies this active circulation of the texts. Although the corpus around the "Verses" was not acknowledged explicitly by late medieval and early modern audiences, e.g. in form of a dedicated collection or commentary upon its nature, it would have been recognised by informed late medieval readers of English alchemica: individual manuscripts containing a high number of corpus texts, notebooks analysing a remarkably large portion of the corpus in the search for reliable alchemical intelligence and numerous annotations across all extant manuscripts debating corpus texts' alchemical content are witnesses to its ubiquity and joint reception by compilers and readers alike. ${ }^{39}$ Considered in its entirety, the corpus of texts associated with the "Verses upon the Elixir" represents a late medieval virtual reference work, a reserve collection and a repository of knowledge.

\subsection{The "Verses upon the Elixir"}

Take erth of erth erthes broder

Water and erth it is non other

And fire of therth that berith the price

And of that erth loke thou be wise

"Verses upon the Elixir", incipit

The poem "Verses upon the Elixir", which comprises a recipe for the philosophers' stone in verse form, was one of the most frequently copied verse texts

38 See also the Introduction above. A number of these texts and manuscripts feature in Keiser, "Heritage". Visualisations of the corpus at the beginning of this chapter (Diagrams I and II) may be used as a mnemonic reference for the following introduction of the individual corpus texts.

39 The notebooks are subject to investigation in Chapter 6 . 
of the late medieval and early modern period.$^{40}$ It survives in a comparatively large number of copies: at least thirty full copies and numerous substantial and minor fragments. The four extant fifteenth-century manuscripts and their sixteenth- and seventeenth-century successors certainly represent only a fraction of those originally in circulation.

Written in the customary cryptic alchemical style the poem details substances and operations, including specific information on measurements, proportions, colour stages of the work and durations of the experiment's parts, in six individual yet interdependent cycles. The first isolates three elements (earth, water and fire) from 'earth' by cold dissolution in aqua nemoris ('water of the wood'), then advises elaboration (i.e. separation of crude and fine parts) and the production of a gum by evaporation. ${ }^{41}$ The subsequent distillation of aqua vitae is followed by the appearance of a red fire from which a black, dry earth emerges, the basis of all following steps (nigredo; ll. 1-20). This black earth is purified until it assumes a bright colour, imbibed with the aforementioned water to turn white (albedo), heated to produce a red substance (rubedo), and imbibed further to produce the stone (an elliptic part of the recipe, ending 1. 38). The second section discusses the alchemical-philosophical underpinnings of the work, among them the importance of the four elements, of 'sperm' as a vital force, and of aqua nemoris as solving agent (ll. 39-54). The third part (ll. 5568) proposes a shortcut to the recipe: sublimation in arsenic, calcination with mercury, combination with aqua fortis, fixation over fire, and imbibition; the produced stone, the recipe tells us, can transform forty times its weight of copper and lead (into gold and silver). The fourth section focuses on aqua vitae derived from two elixirs, which have been made from lead (ll. 69-81). Part five explains the cleansing properties of this water and expands upon the use of a (possibly related) 'oil' for rubrification, before detailing, possibly repeating, the progression of the work from black to red (ll. 82-99). The final section delivers the results: projection of the stone on mercury to transform it into gold (one part on two hundred, 1l. 100105).

${ }^{40}$ Dunleavy, referring to an early edition of the IMEV, identifies the "Verses upon the Elixir" as the fourth most widespread medieval alchemical text after "On Preparing the Philosopher's Stone", Ripley's "Compound of Alchemy", and Norton's "Ordinal of Alchemy": Dunleavy, "Chaucer Ascription," 10.

${ }^{41}$ Information on alchemical processes for this poem, and all texts discussed below, is based on reliable entries in Priesner and Figala, Alchemie, and various other secondary literature, including several works by Principe and Newman (see Bibliography for details). 
The recipe's structure, the intersection of its steps and the repetitive nature of the alchemical practice would have been familiar to its readers from other alchemical writings. For example, George Ripley's near-contemporary "Compound of Alchemy" is presented in twelve 'gates' which divide the manufacture of the philosophers' stone into twelve steps. ${ }^{42}$ While the poem is interspersed with Decknamen for substances and procedures it is noteworthy that allegorical passages in the "Verses" do not make use of traditional personified or populated imagery like hermaphrodites, king and queen, childbirth, or mythical creatures, as many contemporary alchemica do. ${ }^{43}$ But even if actual processes referred to in the "Verses" cannot be identified with certainty due to linguistic ambiguity, both the recipe text and its reader reception suggest that the poem was intended for use in the alchemical workshop and actually employed as such. ${ }^{44}$ As a Gebrauchstext the poem bridges two literary traditions: concise, straightforwardly practical prose recipes often found in margins of medieval notebooks, and alchemical allegories.

The supposed author of the poem "Verses upon the Elixir" is named by Elias Ashmole and some of his contemporaries as 'Pearce the black monk'. There is no evidence of this ascription dating from before the seventeenth century; indeed, some manuscript writers may have taken their information from the Theatrum Chemicum Britannicum; the source for the attribution in the $T C B$, however, is not clear. The only external reference to Pearce in the period of the active circulation of the "Verses", the mid-fifteenth to seventeenth centuries, may be found in another corpus text: "Trinity", a poem which forms part of the Ripley Scrolls (see below), mentions Pearce or his oeuvre as an authority on the alchemical work.

Who is Pearce? Unfortunately no historical evidence is available in the form of other writings or biographical information. His explicit affiliation with the Benedictine order (implied in the designator "black monk") is probably more indicative of a copyist's evaluation of the "Verses upon the Elixir" and alchemy rather than an indication for the existence of an actual

42 TCB, 107-109.

43 On Decknamen and concealment see Principe, "Decknamen," including its bibliography, and Long, Openness, 148. Crosland, Historical Studies, is a relatively early publication focusing on peculiarities of alchemical expression, but outdated. Further literature on Decknamen in specific contexts (and a later period than is of relevance for the "Verses") may be found variously, and much more reliably, in Principe, Secrets, and Newman, Gehennical Fire.

${ }^{44}$ See e.g. a unique prose commentary of the fifteenth century, written alongside the "Verses" in Bod MS Ashmole 759, ff. 124 $4^{\mathrm{r}-\mathrm{v}}$. 
author of that name. ${ }^{45}$ Beyond the text of the "Verses", Pearce remains an early modern legend.

Like so many of the vernacular alchemica of the late medieval period, the "Verses upon the Elixir" developed different versions which circulated simultaneously throughout the entire early modern period. The two main variants of the "Verses" (A and $B_{1}$ ) share substantial textual parts but differ in their rendition (more and less concise), order and, in part, wording of the recipe. Only two couplets are peculiar to the shorter version, A, in comparison with version B. The first (ll. 72-73) references the liquefaction or extraction of aqua vitae from elixirs; its absence in version $B_{1}$ is noteworthy, as it either implies that the water is synonymous with the elixirs, or leaves its production up to the reader's interpretation. The second couplet (ll. 8485 ) relates a conventional religious reference without any obvious necessity or practical purpose. Pithy and practical in nature, version A of the "Verses" would have been ideally suited for use in the alchemical workshop.

Version $B_{1}$ of the "Verses upon the Elixir" expands the same recipe with theoretical sections. It includes nine additional passages (i.e. up to one hundred additional lines) which cover not just practical instructions but the entire scope of alchemical writing in their content. Its religious and philosophical phrases are mostly rhetorical in their discussion of the ideal disposition and pious conduct of the successful alchemical practitioner (e.g. 1l. 87-102); ;6 they often function as transitions between different parts of the poem. Other parts diverge from the alchemical recipe or its description in version A, among them details on natural and chemical principles (1l. 5786), more details on the qualities of aqua vitae (1l. 140-146) and on the transformation of base metal into gold (esp. 1l. 177-192). An introduction to the personified substance 'Mercury' and an allegorical monologue in which 'she' praises her own alchemical qualities forms one of the most substantial amplifications of version $B_{1}(11.116-126,127-138)$. This section also occurs as an individual poem entitled "The Boast of Mercury" in later manuscripts, often verbatim and occasionally as a variant text (see below). Altogether, while not entirely misplaced beside the alchemical furnace, version $B_{1}$ probably best represents the essence of the didactic tradition of alchemical poetry.

$45 T C B, 269,473$ and 487 . The relationship of the clerical orders and alchemy has not been studied in detail to date. Initial impressions may be found in Partington, "Albertus Magnus," 13-14; see also Theisen, "Attraction" and DeVun, Prophecy.

${ }^{46}$ Here and henceforth line numbers in italics refer to version B of the poem. See Table I for details on differences between versions A and B. 
Version B was further rearranged in some copies to alter the sequence of practical steps (version $\mathrm{B}_{2}$ ). Here two medial parts of the poem are positioned towards the end of the poem, wedged into the middle of a section which is peculiar to version B (1l. 57-116 appear after 1. 181). Consequently, all practical steps of the experiment are placed towards the first half of the "Verses" and followed by theoretical and religious passages in the second half. It seems that structure $B_{2}$ was thematically organised to facilitate direct access to the practical parts. It combines version A's pragmatic nature with the alchemo-poetic aspects of version B in its standard form. ${ }^{47}$

Table I: Alchemical procedures in two versions of the "Verses upon the Elixir"

\begin{tabular}{|c|c|c|c|c|c|}
\hline Part & lines & Version A & lines & Version $B_{1}$ & Content \\
\hline \multirow[t]{5}{*}{ I } & $1-8$ & 1 & $1-8$ & 1 & introduction; materials \\
\hline & $9-20$ & $2(\mathrm{~A})$ & $9^{-34}$ & $2(\mathrm{~B})$ & $\begin{array}{l}\text { isolation, dissolution, elaboration, } \\
\text { distillation, nigredo }\end{array}$ \\
\hline & $21-26$ & 3 & $35-40$ & 3 & purification \\
\hline & $27-30$ & $4(\mathrm{~A})$ & $41-48$ & $4(B)$ & further steps \\
\hline & $31-38$ & 5 & $49-56$ & 5 & cibation \& conclusion \\
\hline \multirow[t]{6}{*}{ II } & & & $57-58$ & a & introduction second part \\
\hline & $39-44$ & 6 & $59-66$ & 6 & philosophical basis \\
\hline & & & $61-62$ & $\mathrm{~b}$ & likeness of species \\
\hline & & & $67-76$ & $\mathrm{c}$ & $\begin{array}{l}\text { unnatural procedures, polemic } \\
\text { discussion elements }\end{array}$ \\
\hline & $45^{-54}$ & 7 & $77-86$ & 7 & Aristotelian elements \\
\hline & & & $87-102$ & $\mathrm{~d}$ & religion \\
\hline III & $55^{-60}$ & 8 & $103-108$ & 8 & $\begin{array}{l}\text { sublimation, calcination } \\
\text { grinding/ingression }\end{array}$ \\
\hline
\end{tabular}

${ }^{47}$ Surviving witnesses distribute as follows: Version A: 15 full copies (and substantial fragments, which will be implied when full copies are mentioned henceforth), 2 fragments; Version B: 36 full copies, of which 12 each belong to either Version $B_{1}$ or $B_{2}$, while the remainder do not show markers of either version clearly, mostly because they omit significant passages; and a further four medial fragments. For an overview of witnesses including minor fragments and variants see the Edition towards the end of this book; stemmata are provided there (Diagrams VI and VII). 


\begin{tabular}{|c|c|c|c|c|c|}
\hline Part & lines & Version $A$ & lines & Version $B_{1}$ & Content \\
\hline & $61-65$ & 9 & $109-113$ & 9 & $\begin{array}{l}\text { composition/fixation } \\
\text { cibation } \rightarrow \text { stone }\end{array}$ \\
\hline & $66-68$ & 10 & $114-116$ & 10 & projection 1:40 \\
\hline \multirow[t]{7}{*}{ IV } & & & $117-126$ & $\mathrm{e}$ & introduction Mercury \\
\hline & & & $127-138$ & $\mathrm{f}$ & "Boast of Mercury" \\
\hline & 69 & 11 & 139 & 11 & Saturn \\
\hline & & & $140-146$ & $\mathrm{~g}$ & \\
\hline & $70-71$ & 12 & $147-148$ & 12 & elixeration from Saturn \\
\hline & $72-73$ & $\mathrm{x}$ & & & extraction aqua vitae \\
\hline & $74-81$ & 13 & $149-156$ & 13 & its qualities \\
\hline \multirow[t]{3}{*}{ V } & $82-83$ & 14 & $157-15^{8}$ & 14 & water: albification \\
\hline & $84-85$ & $\mathrm{y}$ & & & religion \\
\hline & $86-99$ & 15 & $159-172$ & 15 & $\begin{array}{l}\text { oil: rubification, citrine gold earth: } \\
\text { nigredo-rubedo final development: } \\
\text { oil, ferment + mercury }\end{array}$ \\
\hline \multirow[t]{3}{*}{ VI } & $100-103$ & 21 & $173-176$ & 21 & projection 1:200 \\
\hline & & & $177-192$ & $\mathrm{~h}$ & fire assay \\
\hline & $104-105$ & 22 & $193^{-194}$ & 22 & concluding couplet \\
\hline
\end{tabular}

Sections not numbered but listed with a letter are peculiar to one version and itemised by letter, $\mathrm{x}-\mathrm{y}$ for version $\mathrm{A}$ and $\mathrm{a}-\mathrm{h}$ for version $\mathrm{B}$.

The content, alternative versions and standard forms of the "Verses upon the Elixir" were firmly established by the end of the fifteenth century. It is not clear which version predates the other; the extraction of condensed texts from more elaborate versions was a common practice for alchemical writings of the medieval period, but the supplementation of short texts with more material and amalgamation of texts were similarly valid writing techniques. In the sixteenth century all versions of the "Verses" entered a phase of subtle adaptation to different manuscript contexts including fragmentation, amalgamation, authorial attribution and translation. It is notable here that the poem's fragments by far outnumber the variant copies: selection and omission were generally more widely practised among copyists than the alteration of poems beyond word level. In their historical reception, the 
three variants of the "Verses" (A, $B_{1}$ and $\left.B_{2}\right)$ did not supersede each other, but were retained, circulated in parallel and even copied side by side in some manuscripts. Some of the later compilers involved in this parallel rendition may have had a literary or antiquarian interest in documenting several versions in the same volume. However, the notebooks preserving many of the earlier copies, and their annotations, imply that many copyists and readers considered the different versions of the "Verses" complementary renditions of an alchemical experiment, constituting multiple approaches to the manufacture of the philosophers' stone that were, hence, to be preserved and dissected for meaning rather than approved or discarded in competition with each other. ${ }^{48}$

\subsection{Texts Associated with the "Verses upon the Elixir"}

\subsubsection{Physical Relations: "Boast of Mercury", "Mystery of Alchemists" and "Liber Patris Sapientiae"}

The poem "Boast of Mercury" and its textual relations, "Mystery of Alchemists" and "Liber Patris Sapientiae", are texts most intimately connected with the "Verses upon the Elixir": medial passages of the "Verses" appear verbatim in these poems. In the sixteenth century the poems developed variants which formed further, different connections with the "Verses upon the Elixir" and its surrounding corpus. In many ways, "Boast of Mercury", "Mystery of Alchemists" and "Liber Patris Sapientiae" form the nucleus of the corpus around the "Verses".

\subsubsection{1. "Boast of Mercury"}

I am mercurye the mighty flos florum I am most worthiest of all Singulorum I am sower of Sol and Lune and Mars I am genderer of Iovis of him be all wars.

"Boast of Mercury", version A, incipit

I am Mercury the mightiest flos florum I am most royall \& richest of all singulorum I am Patronus \& Princeps most royall I am the mother of all manner of mettall

"Boast of Mercury", version B, incipit

\footnotetext{
48 See e.g. Amsterdam, Bibliotheca Philosophica Hermetica MS 199 ('Dekyngston') and BL MS Sloane 1098, both s. xvi, and TCC MS O.2.15, s. xvi-xvii, which contain versions A and $B_{1} ; B L$ MS Sloane 1842 , s. xvi/xvii contains both versions $A$ and $B_{2}$; and other manuscript witnesses contain either of the three variants at any time of their transmission.
} 
An excerpt from version B of the "Verses upon the Elixir", the poem "Boast of Mercury" (short: "Boast") isolates the first-person soliloquy of Mercury personified. The resulting stand-alone poem of twelve lines is a theoretical explanation of the qualities of mercury as an alchemical principle: rather than the common metal, 'philosophical' mercury (and its counterpart, sulphur) form the basis of all alchemical work. The "Boast" emphasises Mercury's status as ruler of all other planets, i.e. material superseding all lesser metals. Individual copies of "Boast" often include an additional, original but unobtrusive couplet in the same style ("I am shee that doth all/ I am shee that men caule"); if these lines carry supplementary information this is not obvious to the modern reader. This early version of "Boast" as an individual poem, which is roughly contemporary with the "Verses upon the Elixir", was circulated anonymously, widely and independently from the "Verses". Notably, copyists were aware of and explicit about its origins: many copies of "Boast" conclude with an "etc.".

"Boast" also developed a completely different and much more substantial variant, version $B$, in manuscripts from the sixteenth century onwards. Version B of "Boast" is related to "Boast", version A only by virtue of its incipit, theme and speaker, and it fluctuates in length between fifty-nine and sixty-two lines. In its contents this version concentrates on the mercurysulphur principle in detail befitting its extended scope: here 'Mercury' not only encompasses all metals but also all types of substances (vegetable, animal, mineral) and elements (ll. 1-8). She acts upon substances (mortification, calcination, revivification, ll. 9-10), is a life-giving principle and embodies black, red and white stages of the work (rubedo, nigredo, albedo; 1l. 11-14), and reacts adversely to some substances (11. 15-19). The poem also incorporates a polemic discussion of elements familiar to readers of the "Verses" (29-35, a-c; "Verses", version B, ll. 69-76)..$^{49}$ Ample space is given to the introduction of Mercury's 'husband' (sulphur), their complementary roles in alchemy, their exclusive compatibility and, once united, inseparability (ll. 20-28, $d-q, 40-52)$. The poem also introduces a third substance, the product (or 'child') of their conjunction, the philosophers' stone, which is specified to multiply by the factor of one thousand (ll. 53-57). This text of "Boast of Mercury" clearly employs a different metaphorical register than the "Verses upon the Elixir", in which similar personifications do not occur beyond the inclusion of "Boast" in version B. Further noteworthy tropes in "Boast of Mercury" are metaphors relating to matrimony (monogamy "by

49 Please see the discussion of this passage in Chapter 2 below. 
the law of England', ll. $d-e$ ), phrases mentioning Christ and God (ll. f, $i$ ); the futility of some alchemists' search for mercury and the alchemical secret (1l. 23-24, 36-39); 'Philosophy' (1. 40), fire (1.44), and sol and luna (1. 5o). The omission or insertion of particular lines (especially ll. $a-q$ ) affects the tenor of the poem and its content in varying ways from one copy to the next.

To complicate matters further "Boast" version B survives in two variants, one of which is even more longwinded than the standard version. This is not due, however, to the addition of lines and content, but to the elaboration of each line. The expanded version contains additional words or phrases in each line-rhetorical devices, perhaps stylistically favoured by some writers but certainly not essential to the poem's contents. The resulting unwieldy lines and irregular rhythm are rare within the corpus around the "Verses".50

I am aer, water, \& also fire

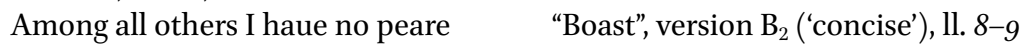

for I am earth water, yea, and I am eyer and fyer,

emong all other in ye world I have no peer.

"Boast", version $\mathrm{B}_{1}$ ('elaborate'), ll. 8-9

Some copies of this elaborate version extend the poem further at the end by adding another 27 lines to the text. This variant ending changes the perspective from Mercury to an unspecified narrator who summarises the contents of the poem. Noteworthy in relation to the poem proper are the ending's explicit mention of alchemy (1.68) and operations (1. 78), of earth (a parallel to the "Verses") as engenderer of all metals, and of sperm as life-giving substance (ll. 71-74, 80). Further, the ending comments upon the nature of elements (ll. 8o-83), upon Mercury's 'soul' (1. 75), and states that its cold calcination is more powerful than fire (1. 83 ) before specifying the thousandfold multiplication to be effected by calcination (1. 85$)$, and the end result as gold (l. 86).

For the sixteenth century in particular, the popularity of "Boast", in all its manifestations, is remarkable. For its copyists and readers, the different versions must have fulfilled different purposes in order to have been copied so regularly, in parallel, without conflict or competition. ${ }^{51}$ They testify to the early modern appetite for alchemical information in different formats.

\footnotetext{
${ }^{50}$ See the contemporary, elaborate variant of "Wind and Water" below. Surviving copies of "Boast" include 21 copies of Version A (four of which are independent, i.e. not incorporated into a text of the "Verses"); and 14 copies of Version $B$ (of which five are texts of variant $B_{1}$, and nine of variant $B_{2}$ ). See also the Edition of the text and Diagrams VIII and IX (stemmata).

${ }^{51}$ I would like to draw particular attention to the notebooks belonging to the physician discussed in Chapter 6 below, which record multiple copies of all versions of "Boast" and the
} 


\subsubsection{2. "Mystery of Alchemists"}

I am mercury the mightiest flos florum I am most riall \& richest of all singulor I am patronas \& princes most ryall I am mother of all manner of mettall

"Mystery of Alchemists", stanza 79

"Mystery of Alchemists", a substantial, anonymous Middle English alchemical poem, forms an indirect extension of the corpus around the "Verses upon the Elixir", as it absorbs substantial passages of "Boast of Mercury" into its text (as well as smaller parts of "Richard Carpenter's Work", variants "Spain" and "Titan Magnesia"). ${ }^{52}$ The common passages now form part of a didactic dialogue between 'father' and 'son', that is, alchemical master and apprentice, concerning the workings of nature, the conditions of alchemical transmutation and the manufacture of the philosophers' stone. The poem's scope varies too much from one copy to the next to justify the definition of a standard version. The Theatrum Chemicum Britannicum prints a text of 296 lines which may be considered a median length for current purposes; the NIMEV states 132 quatrains as a guideline. ${ }^{53}$

Probably written around the same time as the "Verses upon the Elixir", "Mystery of Alchemists" is difficult to place in the corpus of texts in terms of chronology. Similarly, the poem's relation to "Boast of Mercury" and the "Verses upon the Elixir" in terms of originality or derivation is uncertain. All three poems, however, testify to a late medieval enthusiasm for an allegorical first-person monologue of Mercury as personified substance. With approximately twelve extant copies, "Mystery of Alchemists" does not seem to have been as popular as the "Verses" or other texts from the body of late medieval alchemica. ${ }^{54}$

Some scholars considered George Ripley, canon of Bridlington (d. ca. 1490), figurehead of fifteenth-century alchemical poetry, to be the author of "Mystery of Alchemists". ${ }^{5}$ The poem plays a significant role in Ripley's oeuvre, a body of work which includes both authentic and pseudonymous

\footnotetext{
"Verses"; further, BL MS Sloane 2809, of the sixteenth century, which amalgamates versions $A$ and $B_{2}$ of "Boast"; and the assembled manuscripts in Elias Ashmole's collection (now Bod Ashmole MSS), which, taken together, gather the entire tradition of "Boast" texts.

${ }^{52}$ For "Richard Carpenter's Work" see below.

${ }^{53} \mathrm{TCB}, 380-388$.

${ }^{54}$ On extant copies see also the Edition of the text in the final part of this book.

55 See e.g. Singer, Catalogue, item 812; NIMEV, item 4017. This attribution may go back to Bale, Illustrium Maioris, of 1548. On "Mystery of Alchemists" see Rampling, "Catalogue," s.v. item 19 .
} 
texts. It is, however, best considered one of the latter: manuscript evidence indicates that the poem was originally circulated as an anonymous poem with intermittent but consistent attribution to Ripley.

\subsubsection{3. "Liber Patris Sapientiae"}

This worthy science of Alcemy yf thou wilte it learne a litle monye out of thy purse tho[u] muste for beare to buy therwith flos florum it is moste worthyeste and to builde well hir chamber and hir neste [...]

My sonne[,] [mercury] is called the mightiste flos florum And moste royall and richeste of all singulorum She is verie patron, and princes moste royalle And she is verie mother of every mettalle

"Liber Patris Sapientiae", excerpt (stanzas 8 and 36 in TCB)

In the corpus of texts associated with the "Verses", "Liber Patris Sapientiae" represents a sister text to the "Mystery of Alchemists". Also dating from the sixteenth century, "Liber Patris Sapientiae", too, borrows medial passages, at times almost verbatim, from "Boast of Mercury" (here from version B). "Liber Patris Sapientiae" may also be considered a didactic dialogue in verse form, even if the speaker's addressee, a 'son', does not explicitly partake in it.

The full version of the poem takes up a staggering 120 quatrains in Ashmole's edition and varies greatly in scope in its manifestations in manuscripts. "Liber Patris Sapientiae" combines extensive apologetic and advisory sections on secrecy, the social and legal aspects of alchemy and, occasionally, a stanza on alchemical verse with theoretical-allegorical passages on the alchemical work. ${ }^{56}$ Some copies provide a summary of the seven metals' properties (one metal per quatrain), a more metaphorical rendition of the conjunction of mercury and sulphur (albedo, rubedo and projection) and an explanatory paraphrase of earlier parts of the poem. Notably, the text never uses the imperative, and does not stylistically resemble a recipe in any of its parts, even if some of them engage closely with the theoretical underpinnings of the manufacture of the philosophers' stone. Altogether, "Liber Patris Sapentiae" resembles a medley of philosophical-theoretical alchemical lore, possibly a secondary creation pieced together from a variety of other sources in its individual copies.

56 TCB , 194-209 and 487; stanza 21 defends the medium of alchemical verse. The scope of extant manuscript copies is provided in the Bibliography, in the Handlist of Manuscript Witnesses, below. 
Surviving copies of "Liber Patris Sapientiae", only five in number, at times omit pertinent passages and therefore lose the connection with the corpus around the "Verses upon the Elixir", in which "Liber Patris Sapientiae" generally occupies a marginal role. ${ }^{57}$

\subsubsection{Close Bonds: "Exposition" and "Wind and Water"}

Their physical attachment to the "Verses" distinguishes the poems "Exposition" and "Wind and Water" from other texts in the corpus around the "Verses upon the Elixir". Both poems are frequently copied, in sequence, directly after the text of the "Verses", often as if intended to be read in conjunction, at times even without visual separation to form an amalgamated text. As 'physical' extensions of the "Verses upon the Elixir", "Exposition" and "Wind and Water" establish a broader basis for the extension of the corpus in the early modern period.

\subsubsection{1. "Exposition"}

Nowe of this matter to you most clere

An exposicon I do make here

Wheryn I charge you secrete to be

That frynde ne foo do it se

"Exposition", incipit

In style similar to that of the "Verses upon the Elixir" the "Exposition" describes a transmutatory alchemical experiment in a space of sixty-eight lines. Sources do not imply that the poem was ever attributed to an author. With twenty-six full copies and substantial fragments surviving, the "Exposition" establishes its significance in Middle English alchemical poetry through its prominence alone.

The "Exposition" is characterised by its incipit as an exegetic text dependent upon the presence of another, as well as by its appearance in many manuscripts directly after version A of the "Verses". This close association goes back to the earliest surviving, fifteenth-century witnesses of both poems, yet cannot be confirmed intrinsically: their contents depend too much on an interpretation of the language of alchemy to match the experiment described in the "Verses upon the Elixir" with that of the "Exposition". It is perhaps for this reason that the "Exposition" always circulated in physical proximity to one or several poems from the corpus around

\footnotetext{
${ }^{57}$ Surviving witnesses are listed with the Edition of excerpts of the text at the end of this book.
} 
the "Verses upon the Elixir", to maintain a connection which might otherwise be lost quite easily. Only the most modern copies of the "Exposition" appear independently from the "Verses" in manuscripts, an unintentionally autonomous text of uncertain exegetic value once stripped of its point of reference. It is difficult to tell whether this dissociation was a deliberate or accidental process. ${ }^{58}$

The content of the "Exposition" may be summarised thus: after the abovecited introductory lines, with the notable use of the secrecy topos (ll. 14), the poem provides a cursory glossary to the key terms upon which the experiment in the "Verses" is based ('earth', 'water of wood'; ll. 5-6) and emphasises sericon as key ingredient (1. 8) - a substance interpreted variously, by early modern readers, as lead oxide (probably litharge or red lead) or other substances. ${ }^{59}$ A series of processes ensues: the extraction of mercury, and sublimation of its three 'lycours', from a 'gum': the first (aqua vitae, alcohol, here 'attractive mercury'), is won by bain marie (11. 11-20); the second ('our', i.e. philosophical, mercury, lac virginis, or permanent water) has generative powers within the philosophers' stone (ll. 23-40 remind of the "Boast of Mercury") and is employed for the purification of 'earth' (11. 4144); the third, (an oil, 'tincture', sulphur vive, soul of Saturn) is used for the production of a red gum (ll. 45-49). The final section concerns the production of the philosophers' stone and emphasises the importance of the two gums (the aforementioned philosophical mercury and sulphur, 11. 5359) and the two elixirs generated (1l. 6o-64). Other lines, rhetorical glue between the outlined steps, include apologetic appeals to God as the creator of all matter and giver of secrets (ll. $\left.5^{1-52}, 65^{-68}\right)$.

The scribal treatment of the "Exposition" in Elizabethan times is generally careful. The poem does not generate any variant versions and thus constitutes a rarity within its family of related texts. Perhaps afraid of leaving out essential detail, copyists were also reluctant to truncate the "Exposition". It is curious, then, that the scope of the poem's text fluctuates between sixty-seven and seventy lines. The addition of passages to some copies, the removal of those perceived as redundant and the replacement of others account for this subtle yet meaningful variation. The "Exposition" was also subjected to a large number of alterations at word level, particularly variation of the positions of words.

\footnotetext{
${ }^{58}$ In addition to the mentioned full copies the poem survives in three minor fragments; see also the witnesses and stemma (Diagram X) listed with the Edition below.

59 Principe, Secrets, 121, with reference to a forthcoming article by Jennifer Rampling.
} 
Why would generations of alchemist writers constantly reshuffle the words and phrases in an ancillary alchemical poem? One explanation might be that the individual changes relate to aspects of alchemical practice. Indeed, it is noteworthy that only passages not essential to the poem's alchemical content, e.g. religious topoi, are not subjected to alteration. Another likely answer is that they tried to do something which the modern historian still fails to achieve: to match the advice given in the "Exposition" with the text of the "Verses", and to better understand their composite recipe for the philosophers' stone.

\subsubsection{2. "Wind and Water"}

Take wynde and water white \& grene.

and drawe therof lac virginis

Where some it call a water clere the which water hathe no pere

"Wind and Water", version A, incipit

Nowe will I clerely declare vnto you all, the making of our Elixir which we call our stone, truly \& instly howe, herkin euerichone first knowe ye materialls \& propercion of eche one

"Wind and Water", version B, incipit

Thanks to the survival of seventeen extant full copies, the standard version of "Wind and Water" belongs to the group of the most widely circulated Middle English alchemica, both together with and independently of the "Verses upon the Elixir". "Wind and Water" also dates from the mid- to late fifteenth century and is often appended to the "Exposition" (and thus indirectly to the "Verses", version A).

Another anonymous addition to the corpus around the "Verses upon the Elixir", this original, concise version of "Wind and Water" does not seem to describe a full experiment. Its text concerns the distillation of lac virginis (a synonym for philosophical, i.e. alchemically produced, mercury) derived from two elements, 'wind and water'. Notable is the advice to change the receiver (l. 7), preserve a white fume (l. 6) and observe a red, strong fire, possibly the stage of rubedo (ll. 8-9). The Latin ending (ll. 10-13, where applicable) specifies that this last, rubificated substance, the 'menstruum', is philosophical gold, which (it states) may be used for a number of further processes.

"Wind and Water", version A, shows intertextual connections with the "Verses", where six of its lines surface almost verbatim. It is not clear whether "Wind and Water" was intended to represent a summary of the "Verses upon the Elixir" or "Exposition", or to be circulated alongside the two poems to 
elucidate their content; readers often considered "Wind and Water" the final section of the composite poem ("Verses" followed by "Exposition" and "Wind and Water") without commenting on the repetitive nature.

Like "Boast of Mercury", however, "Wind and Water" leaves its most distinctive mark in the history of early modern alchemical writing in its alternative sixteenth-century guise: an extensive poem which introduces the reader to the subject matter in an almost dramatized form and complements version A with more technical detail on procedures, equipment, theoretical background, justification and relevance of the experiment. ${ }^{60}$ Its final lines mark this variant as a recipe for the philosophers' stone (a clearer goal than version A's intended outcome). Version B certainly comprises very dense information in metaphorical terms (with substances personified), but not necessarily a clearly structured series of steps, in the lines between incipit and end. We hear of proportions (one part on nine for male and female substances), procedures (coction and mortification, ll. 10-12); of reactions (contrition into a powder, congelation/ceration and generation of a stone, 11. 13-14) and adaptations: if this stone-'child' is made with the power of his 'father' (sun, i.e. gold, l. 25), it is the king of metals; if made with the 'mother' (moon, ie. silver, 1. 25), it needs to be imbibed further (1l. 15-22). The text is careful to distinguish between common precious metals used for currency and the ideal outcome of this work, their philosophical counterparts (1l. 263o). A transition referring to the authority of the Old Testament (ll. 30-32) leads into the second part of the poem, which starts with a discussion of the hidden nature of the philosophers' stone and its all-encompassing qualities (ll. 33-41; this part reminds of the "Boast of Mercury") and instructs on its congelation, elaboration (removal of the imbibed liquid and other impurities), rubrification by heat and congelation into the red stone (ll. 42-47). The final section (ll. 48-62) comprises more general moral/pious advice on good alchemical practice.

Parallels between versions A and B of "Wind and Water" only become apparent in individual phrases:

Take winde and water, whyte \& also greene/ and like as I meane doo you them together, $\&$ by a limbeck drawe yerof a mylk water clene, and doo it into ye Liquour. Rex Boria et Regina meridie evin thether. "Wind and Water", 11. 5-9

6023 copies of Version A and 5 of Version B are extant today. All surviving witnesses are listed with the Edition of the text. Stemmta are provided in Diagram XI.

${ }^{61}$ Italics editorial. 
This may explain why Version B of "Wind and Water" generally circulated independently from the standard text. Only five full copies and substantial fragments, of a more recent date than witnesses of version A, survive. Nevertheless, the contemporary generation of a few commentaries provides a good impression of the original impact both versions of "Wind and Water" must have had originally on Middle English alchemical poetry and its readers. ${ }^{62}$

\subsubsection{Intertextual Connections: "Richard Carpenter's Work"}

The third major group of poems associated with the "Verses upon the Elixir" entertains subtle yet solid relations with different parts of the core corpus presented above. All four versions of "Richard Carpenter's Work" belong to this group, as well as a fragment variant ("God Angel") and the more ancient prose original of "Richard Carpenter's Work", "Alumen de Hispania". With their adaptation of familiar, recognisable phrases, terms and expressions from the wider corpus around the "Verses upon the Elixir", these texts provide the corpus' sinew, an inner structure that connects various poems in a firm yet flexible way.

The modern umbrella title of "Richard Carpenter's Work" unites four originally separate alchemical poems which circulated independently, often anonymously, and always without a common title (indeed, more often than not, without any title at all) in manuscripts from the second half of the fifteenth century onwards. ${ }^{63}$ To their original readers the recipes presented in these poems would have seemed, if not straightforward, then at least decipherable and, indeed, complementary to one another: even though not all, if any, contemporary readers succeeded in translating "Richard Carpenter's Work" into practical terms, or even wished to experiment in the workshop, they recognised the poems' promise as well as the connections between them, and often tried to unveil their secrets. This is evidenced by annotations and the existence of several parallel copies of the poem's versions and in many manuscripts. ${ }^{64}$

${ }^{62}$ See e.g. New Haven, CT, Yale University, Beinecke Rare Book and Manuscript Library MS Osborn fa. 16, pp. 39b and $41 \mathrm{~b}$.

${ }^{63}$ Altogether there are 74 full copies and substantial fragments, and various minor fragments surviving today. See below on statistics for the individual versions.

${ }^{64}$ Six of the seven manuscripts in Cambridge library holdings alone contain altogether ten copies of three versions of "Richard Carpenter's Work". On the decipherability of Decknamen see Principe, Secrets, 18; on ways of deciphering historical alchemical texts ibid., $143^{-156 .}$ 
The poems' similar incipits - probably the reason for their modern indiscriminate title-are variations on the couplet "Of Spain take the clear light/ the red gum that is so bright"; in the other three variants, the term "Spain" is replaced with metaphorical synonyms for gold ("Titan Magnesia", "Sun" and "Father Phoebus" respectively). These terms will serve as short titles for the individual poems throughout this book.

The identity of the man who lent his name to the title of "Richard Carpenter's Work" has been elusive since the first record of the name appeared in a fifteenth-century manuscript. ${ }^{65}$ This may be the "old manuscript" seen by Ashmole and hence responsible for his declaration of "Titan Magnesia" as "The Worke Of Rich: Carpenter". ${ }^{66}$ Surprisingly, although the name is documented only for this poem and appears sporadically in manuscript copies of the text (and eventually even imported directly into manuscripts from Ashmole's printed version), Richard Carpenter was established as an alchemical author by the end of the seventeenth century.

Antiquarian Elias Ashmole is only one in a long row of scholars who, with varying conviction, attempted to supply the name of Richard Carpenter with biographical information:

I finde that in Anno 1447. John Carpenter then Bishop of Worcester founded the Colledge at Westbury neere Bristoll [...]. Besides this he built the Gatehouse at Hartleborough, a Castle neere and belonging to the Bishop of Worcester; and did severall other Workes of Piety and Charity. This Bishop Carpenter is supposed to be Brother, or neere Kinsman to Richard Carpenter our Author, and accounted an Hermetique Philosopher. He was Contemporary with Norton, and Cannings; and for the most part lived neere unto them, at the aforementioned Westbury[.] ${ }^{67}$

More recently it has been suggested that Carpenter's "brother was the Bishop of Worcester", or an "Oxford graduate, [...] a canon of Westbury-onTrym, and as a West Countryman [...] [who] may have known his fellow alchemist Norton". ${ }^{68}$ With no other conclusive evidence available, however, Richard Carpenter remains "a name to do little more than conjure with". ${ }^{9}$

65 TCC MS 0.2.16, f. $66^{\mathrm{v}}$.

66 TCB, 275 and 487. Ashmole refers to genealogical records and "an old Manuscript (and it was the ancientest Hand-writing I ever saw[)]" (ibid., 473-474); neither can be identified today.

$67 T C B, 473-474$. William Cannings was a wealthy mayor of Bristol, Norton's hometown. On Ashmole and Cannings, see Janacek, "Virtuoso's History," esp. 411.

${ }_{68}$ Ashmole, Theatrum (introd. Debus), xliii; Hughes, Arthurian Myths, 303-304.

69 This fitting expression was coined in a different context in Cooper and Pearsall, "Gawain Poems," 365 . 


\subsubsection{1. "Spain"/“Titan Magnesia"}

Of spayn [or: titan magnesia] take thou thy clere light

The redde gomme that is so bright

Of philosophers the sulphur vif

Callid golde withouten stryf

"Spain”/“Titan Magnesia”, incipit

The first two variants of "Richard Carpenter's Work", "Spain" and "Titan Magnesia", are identical except for the variation in the first line. For the sake of conciseness (and in view of the fact that the Latin source text discussed below is called "Alumen de Hispania") the term "Spain" will be used henceforth to refer to either text unless indicated otherwise.

An alchemical poem of ninety-six lines, "Spain" presents another transmutatory recipe instructing in the manufacture of, as the poem puts it, the "riche rubie the stone of price" (1.84). It begins with the extraction of a tincture from 'Spain', further specified as red gum/sulphur vive/gold, ${ }^{70}$ whereupon a husband and wife (sun and moon, philosophical gold and silver) are amalgamated (ll. 1-11) to generate a (mineral, cf. l. 46) stone with the help of mercury (ll. 12-16). The stone is then subjected to liquefaction, probably by distillation, as the recipe warns that the fume must be preserved (1l. 1723). It also specifies the temperature needed to see a succession of colours in the work as the aforementioned stone decocts and changes its properties (black, white, red and 'citrine', ll. 24-34). The result, an amalgamated, inseparable substance, decocts in a sealed container to generate the animal stone (described with its qualities in ll. 35-46). The remainder of the poem is a long section of more theoretical-advisory content (ll. 47-96, see also the common passages with the "Exposition" below). Noteworthy here is the emphasis on temperature regulation in decoction (1l. 77-78), on books and literacy (ll. 79-81) and the mention of Mary, sister of Moses, as an alchemical authority (ll. 88-90).

"Spain" is indirectly connected with the "Verses" through intertextuality. The poem shares some passages with the theoretical parts of the "Exposition" in a modified yet recognisable form. The following parallels are just one example of such coincidences (italicisation editorial):

ffor fowles in their therewith do fle

and also fisshes swym therewith in the see

70 This helps interpret the term 'magnesia' in the alternative incipit, "Titan Magnesia” and parts of "Father Phoebus": generally in pseudo-Lullian alchemical lore 'magnesia' was a symbolical name for any number of substances, similar in its function to other Decknamen in alchemical literature. Priesner, "Magnesia”. 
ffor moisture of the redde grape

And of the white who can it take

“Spain”, ll. 65-68

Erth is withyn most fyne

Water of Wode aysell of wyne

ffor the moisture of the grape who can it take

And sericon don our maistry make

"Exposition", 1l. 5-8

Since the relevant line does not fit into the metric and rhythmic structure of the "Exposition" it may have originated in "Spain" or a third, shared but unidentified source. More pertinently, such an appearance of familiar elements in different, approximately contemporary alchemica is very common in late medieval and early modern written culture, if in different degrees of congruency. Notably, "Spain" is the only version of "Richard Carpenter's Work" with this quality; all other versions connect with the corpus around the "Verses upon the Elixir" in different ways.

The position of "Spain" within the corpus around the "Verses" is much more complex than simple intertextuality. It also links different parts of the corpus with each other and with an ancient tradition of alchemical literature. Its Latin prose ancestor, "Alumen de Hispania", served as a model for this translation as well as others in the late medieval period. For the history of "Spain" in the late Middle Ages it is significant, firstly, that its English verse version was the first vernacular translation of "Alumen" to gain particular popularity in alchemical circles. Although a fourteenth-century French prose version represents the first vernacularisation of "Alumen", the Middle English poem "Spain" drew a larger audience and more enthusiastic reception. ${ }^{71}$ Secondly, the abovementioned reference to the legendary ancient alchemist and authority Maria (commonly known as "the prophetess" or "the Jewess"), a figure also prominent in annotations of post-fifteenthcentury copies of the "Verses", links "Alumen" and "Spain" with a poem from the Ripley Scroll, "Trinity".72 Both "Alumen de Hispania" and "Trinity" will be discussed in their own right below.

"Spain" proved to be as popular as it was tenacious in manuscript survival. The nineteen extant copies of "Spain" (full texts and substantial fragments)

71 The manuscript containing the French version is CUL MS Ii.3.17, ff. $68^{\mathrm{v}}-70^{\mathrm{v}}$. Readers here often kept separate manuscripts for Latin prose and English verse texts; only occasionally did "Alumen" and "Spain" appear together (TCC MS O.2.16, Bod MS Ashmole 1416). On scribal tactics of the copyist of Bod MS Ashmole 1416, see Barthélemy and Kahn, "Voyages," 492.

72 For Maria, see Patai, "Maria" and especially the more developed version of this article in Patai, Jewish Alchemists, $71 \mathrm{ff}$. See also Chapter 3 below. 
and various smaller fragments include an unusually high proportion of early, fifteenth-century witnesses; copies of "Titan Magnesia" are more rare. ${ }^{73}$ While popular yet not ubiquitous in early modern manuscripts, the individual versions of "Richard Carpenter's Work" certainly encouraged much scribal creativity: some copyists of "Spain" chose to omit a theoretical section (ll. 49-66), others composed variant endings and alternative incipits (for example, by adding the colophon "Geber of Spain saith"), or changed single words and terms in order to improve, one suspects, the poem's contents or style..$^{74}$ In terms of circulation and survival, then, "Spain" represents both the tradition and the expansion of the corpus around the "Verses upon the Elixir".

\subsubsection{2. "Alumen de Hispania"}

Accedens Aaron ad mariam prophetissa sororem suam salutans eam dixit. O prophetissa soror mea audiui siquidem de te multoties quod albificas lapidem in vno die.

Respondit Maria. Vtique o Aaron per diem \& in parte diei.

"Alumen de Hispania", incipit

"Alumen de Hispania", a fifteenth-century Latin translation of a Hebrew, and possibly an even older Arabic text, served as the source text for the Middle English poem "Richard Carpenter's Work", variant "Spain". In this didactic dialogue, Maria shares the secrets of alchemy with Aaron (or Aros), a rather inquisitive "philosopher" of uncertain mythical or historical parentage. Within the dialogue we find discussions of the possibility of albification in a single day or less (ll. 1-13); the production of the great elixir (this coincides with the text of "Spain": the poem omits the general introductory questions of "Alumen" to cut straight to the recipe; ll. 19-29); another, purportedly ancient recipe using mountainous herbs, also referencing 'kibrit and alkibrit' (substances we will encounter again in "Richard Carpenter's Work", variant "Sun"); its product is of vast projecting power (11. 33-50). This is then summed up more pithily (or indeed supplemented with another recipe) by Maria to cheer up the struggling Aaron (ll. 54-61): a gum 'elsarog' is added to the mixture, followed by further explications on the nature of

73 Only four copies of "Titan Magnesia" can be recorded. Twelve fragments are not clearly identifiable as one variant or the other. All witnesses may be found with the Edition of the text in the Appendix. Stemmata for both variants are provided in Diagram XII.

74 The mentioned alterations may be found in the copies of Bod MS Ashmole 1478, TCC MS R.14.45 (2 copies); Bod MS Ashmole 1490. The Edition's critical apparatus records variation on word or phrase level and may be consulted for more detail. 
certain substances used, including moist calces, four stones, a reference to Hermes, a warning about foolish and lengthy nigredo and the futility of trying the work even in a year without the necessary knowledge and divine grace (ll. 63-83). The text closes with Maria's observations on the hermetic vessel, the temperature of the fire in the alchemical work and on true hermetic lore (1l. 84-105).

Some copies of "Alumen" then end in a short Latin poem attributed to Arnold of Villanova, which may be considered a pithy, mnemonic rendition of some of the key phrases from the preceding prose text. ${ }^{75}$ The abovementioned popularity of "Spain" in the fifteenth century may, however, be more due to its ancient ancestry than the attribution of this short verse text to a near-contemporary authority. Together, the prose and verse component of "Alumen" represent the pre-Western roots of alchemy and the didactic poetic style revived in early modern Europe.

The title used here, "Alumen de Hispania", agrees with a popular version of the incipit of the recipe proper (1.20 ff.). The text's author is not stated explicitly in late medieval manuscripts. However, thanks to her incorporation into the text, "Alumen" was consistently associated with Maria ("the prophetess", "the Jewess" or, erroneously, the "sister of Moses"). Incidentally, Maria was to become a figure so prominent in English writing and its general, non-scientific conceptions of alchemy that Ben Jonson's mention of her in his play The Alchemist would have fallen on comprehending ears. ${ }^{76}$

The Latin text of "Alumen de Hispania" survives in at least thirteen copies. There also appears to be a slightly more recent German translation of the text. ${ }^{77}$ A sixteenth-century prose translation into English, copied into at least five manuscripts over the course of the following decades, completes the text's cycle through manuscripts and their media.

Within the corpus around the "Verses upon the Elixir" "Alumen" represents an ongoing yet somewhat outdated genre bearing the authority of an ancient tradition. As a Latin prose text often reproduced in the same manuscripts as English poems from the corpus, it offers a literary, cultural and scientific point of reference to fifteenth-century readers and their successors.

75 Arnold of Villanova, "Carmen," printed in Zetzner, Theatrum Chemicum, 4: 542-543. See also Schuler, Alchemical Poetry, 420-428.

76 Ben Jonson, “The Alchemist," II, i, 80-83. See also Chapter 3 below.

77 Many copies of this text are unidentified due to often ambiguous listings in library catalogues; see Timmermann, "Ungereimtes". Details for witnesses may be found with the Edition of the text. 


\subsubsection{3. "God Angel"}

In the name of the holi trinite now send ws grase so hyt be fyrst god made bope angel \& heuen and alle so the world wyth planets seuen

"God Angel", incipit (BL MS Harley 2407, f. 75²)

Amalgamation and fragmentation generate much of the marginal corpus around the "Verses upon the Elixir". "God Angel", a rather influential variant of "Spain", was created as part of this scribal exegetic creativity right at the start of the manuscript circulation of "Spain". In fact, it first materialises in a manuscript that also contains possibly the first and probably the only surviving fifteenth-century copy of "Titan Magnesia". ${ }^{78}$ The poem comprises original passages and phrases borrowed from the final, 'literary' parts of "Spain", including the abovementioned phrase shared with the "Exposition".

The title used here combines key words from the first distinctive line of the poem (l.3), to distinguish it from a variety of poems with similar incipits: "God Angel" models its incipit on a religious commonplace by invoking the holy trinity to support the alchemical work. This beginning also connects "God Angel" with another poem from the corpus, "Trinity", mentioned twice above because of its references to alchemical authorities (Pearce for the "Verses", Maria for "Spain" and "Alumen de Hispania"). Although otherwise a diluted derivation of corpus poems, "God Angel" is thus a distillate of various connections within the network of knowledge preserved in the corpus around the "Verses upon the Elixir".

"God Angel" is a collection of aphoristic couplets on the divine origins of matter, prerequisites for alchemical success and qualities of the ideal practitioner, permeated with allusions to God as the creator and keeper of secrets. Its practical content is negligible: the text merely mentions three flowers (l. 28, crystalline powders) and the moon/silver as essential to the work (1. 29).

The poem's full scope of forty lines is the same as that of other variants of "Richard Carpenter's Work", even if all except one of the manuscript copies bisect or truncate the text. The second half of the poem (beginning "If thou wilt this work begin ..., l. 23) appears separate from the first part in the earliest witness and was erroneously identified as the single extant copy of a poem entitled "Geber, On the Virtue of the Planets and of the Philosopher's Stone" in an early catalogue. ${ }^{79}$

${ }^{78}$ BL MS Harley 2407.

${ }^{79}$ Information on this original identification for BL MS Harley 2407 , f. $75^{\mathrm{r}-\mathrm{v}}$, in Singer, 
Overall, only three witnesses of "God Angel" survive. It seems that its theoretical, pious advice was eclipsed by other, more practical variants of "Richard Carpenter's Work" in their reception. It is all the more noteworthy, then, that Ashmole includes the poem in his Theatrum Chemicum Britannicum, in isolation from "Richard Carpenter's Work" and the corpus around the "Verses". ${ }^{80}$

\subsubsection{4. "Sun"}

Of the Sonne take the light

The redde gome yat is so bright

And of the mone do also

The whight gome there both to

"Sun", version A, incipit

Of the sonne take the clere light,

the red ston yat is so bright.

The philosophor in all his liffe

called it sonne, \& it is argent vive

"Sun", version B, incipit

"Richard Carpenter's Work" variant "Sun" adds complexity to the corpus around the "Verses upon the Elixir", as it survives in different formats, on several scribal media and in various connections with different parts of the corpus. "Sun", version A, is similar to "Spain" in several respects. Both poems provide practical and theoretical instruction in the alchemical work, possibly even the same recipe for the philosophers' stone, and sixteen of the forty-two lines in "Sun" coincide with the initial part of "Spain".

But "Sun" generally assigns more importance to the documentation of synonymous terms for alchemical substances. Its short variant (ten to twelve lines, a truncated version of the full text) starts with red and white gums (sulphurvive/gold and silver, and here also kibrit and alkibrit; see "Alumen de Hispania" above; ll. 1-8). From these a tincture is extracted before they amalgamate while imbibing aqua vitae (1l. 9-12). The long version continues beyond this line, to explore the nature of the aqua, again specifying common terms by which it is known ('acetum of philosophers', lac virginis, spirit of life, ll. 13-22) and its role in the abovementioned process, followed by a rhetorical conclusion of this part of the recipe (ll. 23-32). The stone now generated is mentioned (1l. 33-36) before the practical parts of the decoction leading to its generation are explained: perfect temperature and a perfectly sealed vessel are of vital importance (ll. 37-42).

Catalogue, was taken from the DIMEV.

$80 T C B, 211$. See the Edition of the text below for witnesses and stemma (Diagram XIII). 
In addition to the shared passages with "Spain", "Sun", version A, connects with the corpus around the "Verses", and the "Exposition" in particular, in a manner which deserves special reflection. Compare, for example, the following two passages:

Acetum yat is goodde and fyne

better to them then any wyne

"Sun", ll. 31-32

Erth is withyn most fyne

Water of Wode aysell of wyne

"Exposition", ll. 5 -6

The cohesion between these phrases is not exactly intertextual, yet their rhyme patterns, terminology and phrasing agree with one another: the passages seem to be interchangeable. This "interphraseology", an extended use of formulaic phrases common to poetry beyond the alchemical, can be observed in the corpus around the "Verses upon the Elixir" in a large number of instances. It will be discussed in the following chapter in more detail. ${ }^{81}$

Both long and short versions of "Sun" form part of the illuminated Ripley Scrolls, though always in one version only; the short version is peculiar to the Scrolls and does not appear in codices. When on the Scroll, "Sun" is implicitly attributed to Ripley and written underneath the imposing opening image of an alchemist holding an alchemical vessel. In this vessel a roundel, or wheel, of circular images depicts the progression of an alchemical experiment. The relation of this image to the text of "Sun", if any, is not clear. The choice of "Sun" as the initial text on the Scroll is nevertheless remarkable given the fact that it does not in itself appear to be special or different from other poems on the Scroll or in the corpus of poems around the "Verses upon the Elixir". ${ }^{22}$

It is noteworthy that individual, anonymous copies of version A of "Sun" in bound manuscripts always render the complete, long version of the text-moreover, only in association with other texts from the corpus around the "Verses". The authorial attribution to Ripley for this poem is restricted to the Scrolls. The production of bound manuscript copies of "Sun" surges around the mid-sixteenth century. But even generally, version A of "Sun" enjoyed enduring popularity: eleven and ten witnesses survive of the long and short version respectively.

Version B of "Sun", another short, related yet essentially different alchemical poem of (for the alchemical practitioner) problematic comprehensiveness, appears independently from version A in manuscripts from the fif-

\footnotetext{
81 See the final section of Chapter 2 below.

82 The Ripley Scrolls are analysed in Chapter 4 below.
} 
teenth century onwards. Version B describes the conjunction of the red stone and argent vive and the addition of the 'bird of life', possibly referring to the cauda pavonis (the state of colour changes in the experiment believed to precede the final albedo $).{ }^{83}$ It then echoes other poems' advice on the preservation of the fumes in this process and ends somewhat abruptly.

Within the written culture of early modern England version B of "Sun" is only marked by a comparatively unenthusiastic reception. ${ }^{84}$ In the corpus around the "Verses" it occupies an ancillary position.

\subsubsection{5. "Father Phoebus"}

Take the father yat phoebus so bryghte that sytteth so hyghe in maiestye with his beames yat shyneth lyghte in all places wheresoeuer he be

"Father Phoebus", incipit

"Father Phoebus" is a true and late, sixteenth-century variant of "Richard Carpenter's Work" of forty lines. The term peculiar to this variant's incipit requires further explanation: Phoebus, an epithet of Apollo, the sun god, could represent the metal gold in general and the philosophers' stone in alchemical contexts. ${ }^{85}$ The fact that the term "phoebus" also occurs in "Spain" (1.26) is not entirely due to coincidence.

In its contents, although formally another recipe text, "Father Phoebus" focuses on theoretical aspects of the alchemical work. Thirty-six of its forty lines are mainly rhetorical phrases. The main focus is on the ingredient, "the father yat phoebus so bryghte”, here also 'homogenye' (1. 13), its role as vital principle (ll.1-14) and its opposing principle (or wife) 'magnesia' (1. 15). After a quatrain announcing the recipe proper (ll. 17-20) the same merely advises the division of gold and refinement of the substance (making the 'thick' 'thin', ll. 21 and 31). The remainder of the poem follows the terminological inclination of "Sun" in its tenor and explains the difficulty of identifying the recipe's substance correctly.

With its alternating rhyme pattern (unique among the poems in the core corpus, and apparently a deliberate, original aspect of the poem rather than a re-arrangement of lines originally grouped in couplets) "Father Phoebus"

\footnotetext{
83 Priesner, "Farben".

84 Only six copies survive, which are listed (as well as copies of all variants of the poem) with the poem's Edition in the final part of this book. See there for the distribution of copies between codices and Scrolls. Diagram XIV in the Appendix provides a stemma.

85 The connection with the philosophers' stone (1. 28) is established in two copies of "Father Phoebus" in BL MSS Add. 5025 (4) and Add. 32621.
} 
stands out among other variants of "Richard Carpenter's Work". As a result of this distinction, not only is "Father Phoebus" more difficult to memorise and conducive to accidental use of identical rhymes in the copying process, but its abundant textual similarities with "Sun" are also obscured - perhaps a desired effect considering their joint appearance on the Ripley Scrolls.

With regard to its supposed authorship, then, the poem "Father Phoebus" shares "Sun"'s implicit attribution to Ripley. Ashmole's historically faithful reproduction of "Father Phoebus" among the texts on the Ripley Scrolls confirms this in print. ${ }^{86}$ The fact that this variant of "Richard Carpenter's Work" was never associated with Carpenter in early modern manuscript copies is also telling. "Father Phoebus" materialised primarily on the Scrolls and had a defined standard text rather than several variants, so that a consistent attribution was comparatively easy to institute and maintain.

On the Ripley Scrolls, "Father Phoebus" is written beside the image of a sun and above a Bird of Hermes, a composite of a bird's body and a king's head. The debatable significance of this position, and association between image and text, resulted in the swap of this poem with "Sun" in one exemplar. ${ }^{87}$

Patterns of survival for "Father Phoebus" mirror those of "Sun", version A, almost completely. And like that of "Sun", the history of "Father Phoebus" is marked by a lack of textual variation, fragmentation or other alteration. This may be due to scribal inertia, an inherent quality of the text which ensured its preservation (as opposed to inviting the composition of variant forms), or to accident. A perhaps pertinent observation, however, is the reciprocal relationship between textual instability and practical content of alchemical poems of this length: within the corpus around the "Verses upon the Elixir" and the family of texts gathered under the title "Richard Carpenter's Work", "Father Phoebus", an essentially theoretical text, seems the most prescriptive, static and reliable poem. ${ }^{88}$

\subsubsection{Peripheral Corporality: "Short Work" and "Trinity"}

The outer boundaries of the fifteenth-century corpus around the "Verses upon the Elixir" are defined by texts which are either modifications of those described above, or, while originally only remotely related, an integral part

\footnotetext{
${ }^{86}$ TCB, $377-378$.

87 San Marino, CA, Huntington Library MS HM 30313.

${ }^{88} 17$ copies survive, only four of them on Ripley Scrolls. See the Edition towards the end of this book for details.
} 
of the corpus in later parts of its history. Their multifaceted histories, roles in the corpus and historical development introduce the questions of orality, literacy and materiality to the history of the corpus around the "Verses": was it a trend of the workshop, outside of manuscript culture, that prompted the texts to change as they did, or could it have been a purely literary reception of the texts which inspired certain adjustments? In the case of the "Short Work" a pithy original recipe expands and grows to be connected with the "Verses", somewhat similar in its textual expansion to the long versions of "Wind and Water" and "Boast of Mercury" discussed above. In the case of "Trinity" the Ripley Scrolls and a contemporary, analytic literature on alchemical texts and authors play an important role. The resulting picture of the variability and malleability of corpus texts mimics the cycles of the original circulation of the manuscripts in which they are written.

\subsubsection{1. "Short Work"}

Yf ye wolle to pys medycyn a plye make first hevy hard hotte \& drye nessche lyght cold \& wete put ham to geder \& make ham mete "Short Work", version A, incipit

Herde hevy hote \& dry put togeder for so did I hote \& moste colde \& wete make them togedir to mete “Short Work", version B, incipit

Take heuy soffte could \& dry Clense him \& callce grind suttly if thou can any good desoule him in water yat is so wodd "Short Work", version C, incipit A poem with a rather elusive role in the fifteenth-century corpus around the "Verses upon the Elixir", the "Short Work" is here named after its early modern description as "a work very short and true". Variations of this line head several sixteenth- and seventeenth-century copies of the text. The poem was mostly circulated anonymously, but was attributed to the scholar and Franciscan friar Roger Bacon in two sixteenth-century copies, an infrequent yet thought-provoking attribution. ${ }^{89}$

Formally recipes of up to ten lines, the original versions of the "Short Work" (A and B) present similar and yet differently phrased alchemical instructions which are not clearly practical or theoretical in nature. They

89 London, Wellcome Institute MS 519; Bod MS Ashmole 1480. 
are, indeed, too short to be instructive, and the tenor reminds of gnomic rather than scientific poetry. Yet the poem proved ideal for insertion into blank spaces, among the sundry scribblings on flyleaves or, in one instance, on a manuscript cover..$^{90}$ Many copies must have been lost, but six and fourteen copies of versions A and B respectively survive today. ${ }^{91}$

On a linguistic level the "Short Work" witnesses scribal emendation at its most active. The few lines that comprise the poem (six to ten lines for versions $\mathrm{A}$ and $\mathrm{B}$ ) show a great amount of variation, including a formless fluctuation of individual words, an always recognisable yet notoriously unstable incipit, a unique rendition on a Ripley Scroll, and various amalgams with commentary texts and different versions of "Richard Carpenter's Work"; the last is also the poem which appears in close proximity to the "Short Work" in early manuscripts. ${ }^{92}$ It seems that the text was considered a rhetorical commonplace which could be replicated and altered on the spot. It is further interesting to note that late copies of "Sun" show some intertextual and physical affinity with version B of the "Short Work". Yet, overall, the short versions of the "Short Work" permeate the corpus around the "Verses" without leaving a lasting impression.

The essential role of the "Short Work" in the corpus around the "Verses upon the Elixir" is only established with the emergence of a long variant in the sixteenth century. Version C of the "Short Work" was copied and circulated independently from the concise texts, and belies its title with a total of ninety-eight lines. With a shift in emphasis towards practicability this version describes a practical experiment in functional, metaphorical and theoretical terms; similarities between versions $\mathrm{B}$ and $\mathrm{C}$ end with the incipit.

The content of the "Short Work", version C, may be summarised thus: a series of instructions moves from the cleansing and grinding of the first line's cryptic substance to its dissolution in aqua nemoris ('water of the wood', which is also used in the "Verses upon the Elixir") and extraction of a tincture ('mercury water', 'oil', ll. 1-8), whereupon the earth ignites or turns red (ll. 9-10). After an interlude mixing advice with another familiar instruc-

90 Bod MS e Mus 63, back cover.

91 Witnesses for the individual versions of this poem, and records of original titles, are listed with the Editions towards the end of this book. See also Diagram XV (stemma).

92 The Ripley Scroll in question is BL MS Add. 5025 (3), which does not contain any other poems. Amalgamation or parallel rendition of "Richard Carpenter's Work" occurs in Bod MS Ashmole 759, Bod MS Ashmole 1416, Bod MS Ashmole 1486, TCC MS R.14.45, BL MS Sloane 288, BL MS Sloane 2176 and the Sloane notebook series under discussion in Chapter 6. 
tion to, "make water of earth \& earth of water", i.e. a division reducing the matter to the four Aristotelian elements (ll. 17 and 20), the recipe continues to induce albedo and nigredo, by calcination, congelation (ll. 22-28), then liquefaction, fermentation and dissolution in aqua vitae (1l. 29-34). The resulting conjunction of a 'soul' and 'body' requires ingression, specifically imibibition with its own distillate (ll. 35-40; qualities described in 1l. 41-44). This section of the poem ends with one stanza on the merits of decoding alchemical recipes for the practitioner (1l. 45-48). Afterwards the recipe instructs the manufacture of antimony from philosophical sulphur, specified as vital force for mercury (11. 49-54), followed by rubrification, the generation of another 'child' out of the two principles' conjunction and its imbibition (ll. 55-63). Two substances emerge, which must be conjoined again (ll.64-66). A long final section (starting l.67) explores textual exegesis for alchemical purposes further, and analyses the meaning of some substances and processes of the preceding recipe in much detail, referencing the Bible and the Turba philosophorum. Most interesting is the final quatrain, which identifies the ashes left in the vessel at the end of the procedure as the desired, precious outcome (ll. 95-98) - a clue not often contained in alchemical recipes with this clarity.

Version $\mathrm{C}$ survives in thirteen full copies and substantial fragments as well as numerous smaller fragments..$^{93}$ On a textual level, extant copies of the "Short Work", version $\mathrm{C}$, show little variation, and any changes that do occur are mostly of a stylistic or rhythmic nature. Finally, with regard to its authorship, Ashmole's attribution of this elaborate version of the "Short Work" to George Ripley cannot be confirmed from manuscript evidence. ${ }^{94}$

Most notably for the present context, the elaborate version shows striking affinities with the "Verses" of the nature described as "interphraseology" above: linguistic patterns, rhyme structures and other echoes between the two poems abound. It seems likely, therefore, that the "Short Work", version $\mathrm{C}$, was written in reaction to the popularity of the "Verses upon the Elixir". The poem may also be another indicator for a sixteenth-century trend of elaboration in alchemical poetry, similar to that already observed for "Boast of Mercury" and "Wind and Water". Although clearly not a product of

\footnotetext{
93 These are listed in the preface to the Edition (final part of this book), together with seven minor fragments.

94 The attribution is only repeated - perhaps prompted by Ashmole's - in London, Lincoln's Inn MS Hale 9o, f. 48v . The "Short Work" is printed in the TCB, 393-396 (long version; attribution repeated in the table of contents on p. 488 ); and 436 (version A).
} 
coincidence, the interaction between all mentioned corpus texts cannot be described completely in terms of causality or chronology. The "Short Work", version $\mathrm{C}$, takes part in a theme that defines the corpus around the "Verses upon the Elixir" in style, language and content.

\subsubsection{Trinity}

In the name of ye trynite

herken here \& ye shall see

myne auctor yat fformyth thys work

both ffirst last bryghte \& dark

"Trinity", incipit

The content of "Trinity", an alchemical poem here named pragmatically after its abbreviated incipit, is more narrative than practical or theoretical in nature. It delivers a chronicle of alchemical authorities as mentors of the poet-narrator's work. The poem possibly dates from around 1500, may have been written for the context of the Ripley Scrolls and, overall, represents a fairly late addition to the fifteenth-century core corpus around the "Verses upon the Elixir". ${ }^{95}$ The role of "Trinity" in the corpus is first established in its physical appearance together with "Sun" and "Father Phoebus" on some Ripley Scrolls, a physical manifestation which defines it more firmly than these two variants of "Richard Carpenter's Work": four of its eight extant copies can be found on the Scrolls. ${ }^{96}$

Given its consistent appearance on the Ripley Scrolls, it is perhaps surprising that the implicit attribution of "Trinity" to Ripley did not supersede the poem's actual, anonymous origins. This may be due to the fact that "Trinity" never became an essential part of a typical Ripley Scroll, but only features as the final text on some of them. In this case shown on the final panel, "Trinity" is surrounded by the image of one or two human figures, supposedly an alchemist and (occasionally) a king or bishop of uncertain relation to the text. In some witnesses "Trinity" was not meant to be included; other surviving exemplars appear to have been cut off at the end, possibly effecting the loss of some copies of "Trinity". Incidentally, Ripley Scrolls contain either the long version of "Sun", version A, together with "Trinity", or its short version without "Trinity"; scribes' decisions to compile either the former, concise Scroll or a relatively long one including the long version of "Sun" and "Trinity" may have been deliberate.

\footnotetext{
${ }^{95}$ Manuscript dating for the earliest surviving codex and Ripley Scroll containing copies of "Trinity" are inconclusive. See also Chapter 4.

96 A stemma (Diagram XVI) and manuscripts are recorded with the Edition of the text.
} 
It is also possible that Elias Ashmole recognised this scribal rationale, as he did not print "Sun" or "Trinity" together with Ripley Scroll texts, nor indeed elsewhere in the Theatrum Chemicum Britannicum. By extension, Ashmole then does not seem to have considered "Trinity" and "Sun" a part of the Middle English alchemical literary legacy—he did not choose to include the texts in spite of their existence in manuscripts, outside of the Scroll context, of which he must have seen several in the course of his editorial work.

Within the corpus around the "Verses", however, "Trinity" occupies the role of keeper of the alchemical literary heritage in yet another way. The authors named in the poem to certify the excellence of "Trinity" (or of texts preceding it) include one "Pearce", the supposed author of the "Verses". Significantly this confirmation of Pearce as an author occurs prior to the seventeenth century, and therefore prior to allusions to Pearce in extant copies of the "Verses upon the Elixir". "Trinity" also refers to "the sustre of moyses mary prophetiss[a]" (1. 14), the female alchemical authority at the heart of the tradition of "Richard Carpenter's Work", variant "Spain" and its ancestor, "Alumen de Hispania". Uniquely, in the corpus around the "Verses", "Trinity" is both a part of the corpus and a witness of its history.

\subsubsection{Additional Poems from the Ripley Scrolls: "On the ground", "In the sea", "I shall you tell"}

With their allegorical depictions of the alchemical work, the Ripley Scrolls' illuminations are the most famous manifestation of alchemical illustrations of early modern England. As receptacles for texts from the corpus around the "Verses", the Ripley Scrolls are markedly different from the bound codices that constitute the more common medium of preservation. Apart from "Richard Carpenter's Work" variants "Sun" and "Father Phoebus" (and, occasionally, "Trinity") the Ripley Scrolls contain three poems which probably originate on the Scrolls: "On the ground", "In the sea" and "I shall you tell" (all named after their incipits here). Like the Ripley Scrolls, all three poems date from the late fifteenth or early sixteenth century and are essentially anonymous, in spite of their indirect attribution to Ripley. These three poems, introduced briefly below, are essentially peripheral to the corpus around the "Verses" and complement the core corpus in familiar yet informative ways. ${ }^{97}$

97 Chapter 4 introduces the Ripley Scrolls in much more detail. On alternative renderings of the alchemical content of all three poems, see Rampling, "Alchemy of the Ripley Scrolls" and McLean, Study Course. 


\subsubsection{1. "On the ground"}

One the grownde there is an hill allsoe a serpente within a well his tayle is longe with winges wide all readye to flee by everye side

"On the ground", incipit

"On the ground" is a text as substantial in length as the major texts surrounding it ("Sun", version A, particularly when it appears in its long variant, and "Father Phoebus"). As a recipe text it may appear slightly more obscure, but certainly related in tone and content to other texts from the corpus around the "Verses upon the Elixir".

From a modern perspective, it is hard to tell whether the poem describes a full recipe or is intended to present a collection of more selective advice, held together by rhetorical phrases and in need of supplementation by other texts: it speaks of a substance (metaphorically represented by a serpent or dragon, ll. 2 and 11) buried in a well, i.e. a liquid, which must be kept safe (in a closed vessel) to preserve the essence of the stone (ll. 1-8). The nature of all mentioned ingredients is discussed in terms of the four elements (ll. 13-18). Putrefaction into a black substance is succeeded by mortification, described as fermentation ('round bladders'; ll. 19-26). The poem ends with albedo by ablution with the original liquid and imbibition, and reference to a white and red stone (ll. $27-36)$. The relation between the poem and its surrounding images - a green dragon eating a black toad, painted at the foot of a fountain - also remains open to interpretation. ${ }^{98}$

\subsubsection{2. "In the sea"}

In the Sea withouten lees standeth the birde of Hermes eatinge his winges variable and maketh himselfe full stable

"In the sea", incipit

"In the sea", a concise poem of just twelve lines, is the only poem present on all extant Ripley Scrolls. This may be due to its medial position on the Scroll, which made it less prone to material loss, or indeed to its function on the Scroll, where it serves as a transition between texts and images yet occupies a stable position beside the image of the Bird of Hermes to which its incipit refers. This Bird of Hermes is depicted as a large hybrid of a variable

98 Fifteen copies survive, only two of them in codices, not Scrolls; see also the Edition below. 
bird body (at times akin to a pigeon, in other renditions a bird of prey or chicken) and the head of a bearded king, about to eat his own wings.

The poem describes a related alchemical process in similarly metaphorical terms: a description of the bird's auto-ingestion (dissolution or corrosion) in a liquid (the 'sea') precedes a note on albedo, rubedo and the philosophers' stone. It closes with a formulaic couplet acknowledging God as inspiration. It seems that "In the sea" explains, supplements and yet obscures the image's meaning at the same time. ${ }^{99}$

\subsubsection{3. "I shall you tell"}

I shall you tell without leisinge.

howe and what is my generation.

homogenia is my father.

and Magdnetia is my mother.

"I shall you tell", incipit

"I shall you tell", an alchemical soliloquy in the manner of "Boast of Mercury", consists of thirty-eight lines of information on the theoretical background of alchemy and the nature of the "Serpent of Arabia", supposedly the product of the experimentation described and depicted on the Ripley Scroll. Elements of its text worth mentioning here are the quartet of 'homogenie', 'magnesia', 'azoth' and 'kibrit' (the last reminiscent of the term in "Alumen" and "Sun"; 1l. 3-6); the 'serpent of Arabia', tamed by sun and moon (possibly philosophical mercury and sulphur) and weighed down by its wings, producing a 'blood' (red liquid solvent; 1l. 7-22); and the final lines, which reference the trinity, three substances combined in one, possibly an allusion to the three stones (animal, vegetable and mineral; 1l. 34-38).

The poem is written underneath the image of a dragon whose chest bleeds into a transparent ball symbolising an alchemical vessel, which contains three black balls and a formerly clear liquid. A relation between image and poem is plausible if not plain. While "In the sea" and "On the ground" also appear in bound manuscript volumes in later parts of their transmission, and then without accompanying illustrations, the influence of "I shall you tell" does not extend as far beyond the Ripley Scrolls. ${ }^{100}$

\footnotetext{
99 Survival statistics are the same as for "On the ground": fifteen witnesses, thirteen of which are found on Ripley Scrolls. The Edition below provides a list of extant copies.

100 Fifteen copies survive, only one contained in a codex; see also the Edition of the text in the Appendix.
} 


\subsubsection{Added Ingredients: "Lead", "Thomas Hend" and "Terra Terrae Philo- sophicae"}

The general sixteenth-century taste for alchemical recipes, fuelled by an underlying desire to convert writing into practice, resulted not only in the generation of poems like those introduced above but also in the copious production of related commentaries, secondary texts, ancillary writings and interpretations. In relation to the "Verses upon the Elixir" two prose texts ("Lead" and "Thomas Hend") constitute such an extension of the corpus. Although not appearing as ubiquitously in manuscripts as critical annotations, these two texts left a distinguished mark in manuscripts surrounding the corpus. Another prose text, a Latin prose translation of the text of the "Verses upon the Elixir", entitled "Terra Terrae Philosophicae", rounds off the extended history of the corpus in the later parts of its history. Consequently, the following introductions complete the inventory of the corpus around the "Verses upon the Elixir".

\subsubsection{1. "Lead"}

Take [Saturn] and beate it as thin as yow can, then take aqua vitae viniger distilled, that is rectefyed, and putt these thynne plates into the [aqua] vitae

"Lead", incipit

This anonymous, untitled yet substantial prose text of the sixteenth century describes an experiment with lead, the substance chosen to designate its title for current purposes. ${ }^{101}$ The text presents a self-contained recipe. Its procedure starts with the immersion of pulverised particles of lead in 'aqua vitae vinegar distilled' (aqua vitae rectificata) in a sealed vessel, so that it albifies and can, once strained, be distilled by bath to leave a white residue. This is distilled again on a low heat to leave a red or yellow residue in the alembic. Once the receiver has been changed this red 'aqua oleum' is increased until it yields an 'earth', which, in turn, is albified by calcination, then imbibed with the distillate of the previous step to conclude the albedo. Rubedo is achieved by imbibition with the red water. Projection upon silver and casting upon impure substances ensues; the recipe promises transmutation into silver (this part ends in 1.33). For the red work the process is repeated with red oil, projection upon gold, and the transmutation of lead into gold (ll. 34$38)$.

101 One erroneous ascription of this anonymous text to Chaucer, in a manuscript of the early sixteenth century, is discussed in Timmermann, "New perspectives". 
It is significant that the recipe then refers to the "Verses upon the Elixir" as an authority for part of the process described: "and this accordeth to the worke in ryme: Earth of earth and erthes brother" (1l. 42-44). The remainder of the text analyses the given recipe through this perspective, trying to match its own recipe with the "Verses". More pertinently for the current context, "Lead" forms part of a literature influenced by the "Verses", and is unusual in its straightforward acknowledgement of its source of inspiration. "Lead" thus lends the "Verses" authority.

Some scribes explicitly mark "Lead" as a text to be read in conjunction with the "Verses upon the Elixir". ${ }^{102}$ In practice, the text is written almost invariably directly before or after the "Verses"; only one of its six surviving copies appears physically isolated in a sixteenth-century manuscript. ${ }^{103}$ This symbiosis, even if one-sided, mirrors the dependency of the "Exposition" and "Wind and Water" on the "Verses" in earlier manuscripts.

\subsubsection{2. "Thomas Hend"}

tak apottell of vinegre distillyd in a vessell of glasse \& put there in 3 [pound] of rede leade \& styre yt well \& lette yt stond 3 dayes sterynge yt every daye often tymes

"Thomas Hend", incipit

This tract, entitled "The conclusion of Mr Thomas Hend for the same thing” (here also "Thomas Hend"), appears generally attached to "Lead" in extant manuscripts. ${ }^{104}$ Its title describes exactly its purpose and contents: "Thomas Hend" provides an alternative rendition of the experiment described in "Lead" and forms another secondary, if slightly longer and more detailed bond with the "Verses". Despite a consistent attribution history, the identity of author Thomas Hend remains mysterious. No other works, historical records or information on Hend's life are available.

Similarly unfortunate is the fact that clear parallels between the three relevant texts elude us: without the physical association with "Lead", and thence the "Verses", "Thomas Hend" would be an unlikely relation to the

\footnotetext{
102 For example, the copyist adding "Lead" after the "Verses" in BL MS Sloae 288 provides a segue between the texts: "Note well yf you make the ffire to much your matter will ascende into the limbecke, and therfro decende into the receptorye as white as any milke that euer you sawe" (f. $164^{\mathrm{v}}$ ). Its predecessor, BL MS Sloane 1842, not only has that note, but also precedes "Lead" with the note "Explicatio precedentium versuum" (f. $\left.12^{\mathrm{r}}\right)$.

${ }_{103}$ BL MS Sloane 1095. All surviving witnesses are listed with the Edition towards the end of this book.

104 Three of its four surviving copies follow "Lead": BL MS Sloane 1842, London, Wellcome Institute MS 577 and BL MS Sloane 288 (in roughly chronological order); see also the information listed in the Appendix, with the texts' Editions.
} 
"Verses upon the Elixir". Its recipe is perhaps noteworthy for details of substances and processes referenced more elusively in both the "Verses" and "Lead": "Thomas Hend" uses three pounds of lead, which he specifies to be red lead (lead oxide, 1. 2); and names the dry matter first left after distillation to be anima saturni (l. 8). The text advises frequent stirring (ll. 3-4), later with a hazel stick (l. 53), straining with a filter (l. 4), adds that distillation should be by alembic (l. 5), and the dissolution of the anima saturni in 'oxen bladders', tied shut and suspended in cold water (1l. 11-13); describes the use of a glass still 'with his alembic well joined' in the heat of ashes (ll. 14-15) and the resulting 'oil' to be appearing 'by the nose' (l.18). Methods described include evening out matter with one's fingers (ll. 22-23) and the use of a 'wire measure' (ll. 23-28), weighing by counterpoise (ll. 29-31) as well as various other measurements by proportion, the observing of a rattling sound in the vessel 'as it were small stones' (ll. 37-40) and the breaking of a glass 'over a clean vessel', undoubtedly very practical advice (l. 66). "Thomas Hend"'s vocabulary is more extended than that of the text's predecessors; examples are the explicit mentions of a crucible (l. 22), a pot (l. 25) and a 'rotund of glass with a long neck' (1l. 29-30).

Overall, however, both as an isolated text and within the network of the corpus around the "Verses", "Thomas Hend" appears an afterthought most remarkable for its existence as an exegetic text on the "Verses", a poem whose origin precedes this text by more than a century. Its attention to detail, including the meticulous reference to the "Verses upon the Elixir", leave an impression of how alchemical poems like the "Verses" were transmitted and received, in a practical context no less, for an extended period of time.

\subsubsection{3. "Terra Terrae Philosophicae"}

Accipe terram de terra et fratrem terrae quae non aliud est quam Aqua et terra, et ignis de terra pretiocissima Atque in hac terra eligenda fac vt sis prudens.

"Terra Terrae Philosophicae", incipit

"Terra Terrae Philosophicae", the final addition to the late corpus around the "Verses", is a sixteenth-century Latin translation of the "Verses upon the Elixir", version A, complete with the "Exposition" and "Wind and Water". As a translation this text is much more deliberate and programmatic in nature than the prose texts previously introduced. Its purpose is obvious in, and ideally fulfilled with, its systematic attribution to George Ripley. ${ }^{105}$ The irony

105 Rampling, "Catalogue," s.v. item 29. It is interesting to note the seventeenth-century 
of attributing a Latin prose text based upon a Middle English alchemical poem to an iconic Middle English alchemical poet must have escaped its original scribes. Surviving manuscript copies date from the late sixteenth and seventeenth centuries, at a time when the body of Middle English alchemica was past its heyday and alchemical readers developed a revived penchant for Latin, 'authorised' literature, including new writings imitating their ancestry. ${ }^{106}$ Unlike their predecessors, those involved in the production and reproduction of Latin texts based on works from the corpus around the "Verses" do not seem to have been aware of the corpus as a corpus. Thus, here and elsewhere in the corpus, texts originally associated with each other assume new guises and are dissociated from each other without difficulty or, indeed, readers' protest.

"Terra Terrae Philosophicae" concludes the evolution of the corpus and, more generally, alchemical literature when it is printed along with Ripley's collected works in $1649 .{ }^{107}$ As such, "Terra Terrae" is a relatively late addition to the Ripleian corpus: a famous printed collection from the mid-sixteenth century does not include this text, as Ashmole points out correctly in his commentary on the "Verses" in the $T C B .{ }^{108}$ However, it appears with Ripley's works in a list in 1619, from which the 1649 publication may have taken its cue. ${ }^{109}$ At that point the text's value is anchored on names like Ripley's and its form is fixed in print. In retrospect it is the swan song of the corpus around the "Verses" and the tradition of alchemical poetry.

translation of "Terra Terrae" into French (e.g. Paris, Bibliothèque Nationale MS Français 19074 (Saint-Germain français 1645)), and into English (e.g. BL MS Sloane 3732, dated for 1669).

106 See the final part of Chapter 3 below. Witnesses consulted are listed with the Edition of the text in the Appendix; some could not be seen in person in preparation of this book. As for "Alumen de Hispania" a number of witnesses have not been identified to date.

${ }^{107}$ Ripley, Opera, 314-322.

108 TCB, 473.

109 Pitts, Relationum Historicarum. 